\title{
Comparison of nitric oxide measurements in the mesosphere and lower thermosphere from ACE-FTS, MIPAS, SCIAMACHY, and SMR
}

\author{
S. Bender ${ }^{1}$, M. Sinnhuber ${ }^{1}$, T. von Clarmann ${ }^{1}$, G. Stiller ${ }^{1}$, B. Funke ${ }^{2}$, M. López-Puertas ${ }^{2}$, J. Urban ${ }^{3, \dagger}$, K. Pérot ${ }^{3}$, \\ K. A. Walker ${ }^{4}$, and J. P. Burrows ${ }^{5}$ \\ ${ }^{1}$ Institute for Meteorology and Climate Research, Karlsruhe Institute of Technology, Karlsruhe, Germany \\ ${ }^{2}$ Instituto de Astrofísica de Andalucía, CSIC, Granada, Spain \\ ${ }^{3}$ Department of Earth and Space Sciences, Chalmers University of Technology, Gothenburg, Sweden \\ ${ }^{4}$ Department of Physics, University of Toronto, Toronto, Canada \\ ${ }^{5}$ Institute of Environmental Physics, University of Bremen, Bremen, Germany \\ $\dagger$ deceased, 14 August 2015
}

Correspondence to: S. Bender (stefan.bender@kit.edu)

Received: 8 October 2014 - Published in Atmos. Meas. Tech. Discuss.: 18 December 2014

Revised: 27 August 2015 - Accepted: 8 September 2015 - Published: 12 October 2015

\begin{abstract}
We compare the nitric oxide measurements in the mesosphere and lower thermosphere $(60$ to $150 \mathrm{~km})$ from four instruments: the Atmospheric Chemistry ExperimentFourier Transform Spectrometer (ACE-FTS), the Michelson Interferometer for Passive Atmospheric Sounding (MIPAS), the SCanning Imaging Absorption spectroMeter for Atmospheric CHartographY (SCIAMACHY), and the SubMillimetre Radiometer (SMR). We use the daily zonal mean data in that altitude range for the years 2004-2010 (ACEFTS), 2005-2012 (MIPAS), 2008-2012 (SCIAMACHY), and 2003-2012 (SMR).

We first compare the data qualitatively with respect to the morphology, focussing on the major features, and then compare the time series directly and quantitatively. In three geographical regions, we compare the vertical density profiles on coincident measurement days. Since none of the instruments delivers continuous daily measurements in this altitude region, we carried out a multi-linear regression analysis. This regression analysis considers annual and semi-annual variability in the form of harmonic terms and inter-annual variability by responding linearly to the solar Lyman- $\alpha$ radiation index and the geomagnetic Kp index. This analysis helps to find similarities and differences in the individual data sets with respect to the inter-annual variations caused by geomagnetic and solar variability.
\end{abstract}

We find that the data sets are consistent and that they only disagree on minor aspects. SMR and ACE-FTS deliver the longest time series in the mesosphere, and they agree with each other remarkably well. The shorter time series from MIPAS and SCIAMACHY also agree with them where they overlap. The data agree within $30 \%$ when the number densities are large, but they can differ by 50 to $100 \%$ in some cases.

\section{Introduction}

Climate models aim to predict the trend of Earth's climate, considering the composition of the atmosphere. This composition is influenced by a number of factors, including anthropogenic emissions and solar variability. To disentangle these effects, the evaluation of the solar influence is important. Solar particles and soft solar X-rays produce nitric oxide (NO) in the mesosphere and lower thermosphere (MLT, 50 $150 \mathrm{~km}$ ) (Barth et al., 2003). Thus, the NO content in this atmospheric region indicates how much solar activity impacts the atmospheric composition and how important solar variability is in climate models.

To relate atmospheric composition changes to solar activity, global NO measurements over long time periods deliver important information. These data are provided by satellite 
instruments using different measurement methods. The consistency of these measurements is crucial for using the results for further work, for example to validate climate models and to find climate-relevant forcing parameters. We compare the daily zonal mean NO number densities from four space-borne instruments: the Michelson Interferometer for Passive Atmospheric Sounding (MIPAS, infrared limb emission) and the SCanning Imaging Absorption spectroMeter for Atmospheric CHartographY (SCIAMACHY, UV-visNIR limb and nadir emission) on Envisat, the Sub-Millimetre Radiometer (SMR, sub-millimetre limb emission) on the Odin satellite, and the Atmospheric Chemistry ExperimentFourier Transform Spectrometer (ACE-FTS, infrared solar occultation) on SCISAT. The aim of this comparison is to answer the question of whether zonal mean data sets from different instruments consistently constrain the nitric oxide in the MLT.

Continuous global NO measurements in the MLT region are still rare, and, with the loss of the Envisat satellite in April 2012, two important instruments are missing. With the end of MIPAS and SCIAMACHY measurements, only ACE-FTS and SMR continuously measure NO between 80 and $120 \mathrm{~km}$. From these two, only SMR delivers global data. ACE-FTS, however, offers only limited latitudinal coverage since it observes solar occultations, scanning the atmosphere at sunrise and sunset. There are still more satellite instruments measuring NO in the middle atmosphere: OSIRIS, SABER, and SOFIE. However, OSIRIS measures only between 85 and $100 \mathrm{~km}$, and SABER only above $100 \mathrm{~km}$. SOFIE is another solar occultation instrument and therefore also covers only a limited latitude range, similar to ACE-FTS.

The instruments are introduced in Sect. 2. In a first comparison step, we compare zonal daily mean distributions in an altitude range from 75 to $115 \mathrm{~km}$ (Sect. 3). In that section we analyse the time-latitude morphology of the NO number densities at different times of solar activity, from low (2008/2009) to moderate (2010/2011). In Sect. 4 we directly compare the time series of NO number densities at selected geographic locations. This more quantitative comparison emphasises differences which cannot be detected in the morphological comparison. We further compare daily mean vertical profiles in order to detect differences that may result from the different retrieval strategies (Sect. 5). In Sect. 6, we extend the comparison towards derived diagnostic quantities of particular scientific interest, for example regression coefficients for the contribution of Lyman- $\alpha$ and the geomagnetic Kp index. In the Conclusions (Sect. 7) we evaluate the consistency of the analysed data sets.

\section{Instruments}

Here we briefly introduce the instruments and MLT NO data sets used in this comparison study. In particular, we focus on the typical features of the measurements, such as satellite or- bits, spectral ranges, MLT measurement schedules, retrieval algorithm and references, as well as uncertainty estimates. At the end of this section, we summarise the instruments and data characteristics in Table 1 and the known uncertainties in Table 2.

\subsection{Envisat/MIPAS}

Two of the instruments considered here, MIPAS and SCIAMACHY, are on board the now-defunct European research satellite Envisat. This satellite had been orbiting on a sunsynchronous orbit at $800 \mathrm{~km}$ and at Equator-crossing times of 10:00 and 22:00 since 2002. Communication to the satellite was lost in April 2012, which is therefore the latest date for which MIPAS and SCIAMACHY data are available.

MIPAS is an infrared Fourier transform spectrometer. It has a spectral range from 4.15 to $14.6 \mu \mathrm{m}\left(685-2410 \mathrm{~cm}^{-1}\right)$, and the spectral resolution was $0.0625 \mathrm{~cm}^{-1}$ during the relevant time period. The instrument has an instantaneous field of view of $3 \mathrm{~km}$ in the vertical and $30 \mathrm{~km}$ in the horizontal direction.

MIPAS measured atmospheric emissions in a limb observation geometry (Fischer et al., 2008). The instrument provided two special observation modes dedicated to the middle atmosphere (MA, 18-102 km) and upper atmosphere (UA, 42-172 km) (Raspollini et al., 2013). After a test phase of 12 measurement days from January 2005 to October 2007, about 1 day every 3 months, the measurements using these modes were scheduled regularly on 2 days every 10 days of nominal mode measurements $(7-72 \mathrm{~km})$ beginning November 2007. In this study, we use only the dayside half-orbit (downleg, a.m.) MIPAS-UA measurements, which amount to 199 measurement days with about 500 scans per day from 21 January 2005 until 30 March 2012.

The NO data used here were produced using the MIPAS data processor developed at the Institute of Meteorology and Climate Research (IMK) in cooperation with the Instituto de Astrofísica de Andalucía (IAA) (von Clarmann et al., 2003). The retrieval is based on constrained multi-parameter non-linear least-squares fitting of observed to calculated radiance spectra. The retrieval processor was extended to apply to non-local thermodynamic equilibrium (Non-LTE) emissions (Funke et al., 2001), which is particularly important for NO retrievals. The vibrational, rotational, and spin level populations under Non-LTE were modelled by the Generic RAdiative traNsfer AnD non-LTE population Algorithm (GRANADA) (Funke et al., 2012) during each iteration of the retrieval.

NO in the altitude region of interest $(70-120 \mathrm{~km})$ is derived from the fundamental NO band emission at $5.3 \mu \mathrm{m}$. The retrieval of NO in the middle atmosphere (up to $\sim 100 \mathrm{~km}$ ) is described in detail in Funke et al. (2005). The NO data used here (versions V5r_NO_520 (MA) and V5r_NO_620 (UA)) were measured from January 2005 to April 2012, when MIPAS used a slightly degraded spectral resolution. The data 
version described in Funke et al. (2005) has been substantially improved as summarised in Funke et al. (2014), and the present version includes these improvements.

The single-profile vertical resolution of NO in the 70$100 \mathrm{~km}$ region is $15-20 \mathrm{~km}$, and the single-profile precision ranges from $\sim 50 \%$ at $70 \mathrm{~km}$ to $\sim 30 \%$ at $100 \mathrm{~km}$. In general, MIPAS has low sensitivity to NO outside of the polar winter region (latitudes greater than $50^{\circ}$ ) at altitudes of $70-90 \mathrm{~km}$. Systematic errors in the NO volume mixing ratio (VMR) in this region amount to around $10 \%$.

The retrieval of NO in the upper atmosphere (100-170 km) is described in detail in Bermejo-Pantaleón et al. (2011). Temperature and nitric oxide mixing ratio profiles are retrieved jointly in this region. The typical single-measurement precision of NO in this region is $10-30 \%$ for high geomagnetic activity, increasing to $20-50 \%$ for low geomagnetic activity. The vertical resolution is $5-10 \mathrm{~km}$ for high geomagnetic activity and degrades to $10-20 \mathrm{~km}$ for low geomagnetic activity. For extra-polar and low geomagnetic activity, a potential systematic bias in the night-time NO version V4O_NO_611 profiles was identified (Bermejo-Pantaleón et al., 2011). This bias is caused by smoothing errors and was corrected in the current version, V5r_NO_620, by using an appropriate a priori NO profile for night-time conditions. The retrieved NO abundances in the thermosphere depend strongly on the assumed atomic oxygen above $120 \mathrm{~km}$, which was taken from the NRL-MSISE-00 model. Other systematic errors, such as the uncertainties in the atomic nitrogen and the propensity for spin-conserving collisions, which largely control thermospheric spin non-LTE distributions, lead to minor systematic errors of $5-10 \%$.

\subsection{Envisat/SCIAMACHY}

SCIAMACHY (Burrows et al., 1995; Bovensmann et al., 1999) is the other instrument on Envisat. It is a limbsounding UV-vis-NIR spectrometer with eight channels from 230 to $2300 \mathrm{~nm}$ and a spectral resolution from 0.22 to $1.48 \mathrm{~nm}$. From July 2008 until the end of Envisat in April 2012, it comprised a special mesosphere-lowerthermosphere mode (MLT, 50-150 km) which was scheduled for 1 day every 2 weeks.

Nitric oxide is retrieved by observing the NO gamma bands with SCIAMACHY's UV channel 1 (230$314 \mathrm{~nm}$ ) (Bender et al., 2013). The limb scans from the MLT mode delivered the NO number densities with a vertical resolution of $5-10 \mathrm{~km}$ at altitudes from 70 to $150 \mathrm{~km}$. The average horizontal distance between the individual limb scans was about $7^{\circ}$. The tomographic orbit retrieval was carried out from 60 to $160 \mathrm{~km}$ and from $90^{\circ} \mathrm{S}$ to $90^{\circ} \mathrm{N}$ on a fixed $2 \mathrm{~km} \times 2.5^{\circ}$ altitude-latitude grid. The average single orbit measurement error amounts to about $30 \%$. Systematic errors amount to $7 \%$ from uncertain spectroscopic data, $3 \%$ from uncertainties in the solar spectrum (Chance and Kurucz, 2010), and about $10 \%$ from temperature uncertainties.

The SCIAMACHY retrieval derives NO number densities. Here we use the NO data version 2.0; overall, SCIAMACHY contributes the daytime data from 78 MLT measurement days from 26 July 2008 until 30 March 2012 with about 450 scans per day.

\subsection{SCISAT/ACE-FTS}

ACE-FTS is a Fourier transform spectrometer on board the Canadian Atmospheric Chemistry Experiment (ACE) satellite (Bernath et al., 2005). It covers a spectral range from 2.2 to $13.3 \mu \mathrm{m}\left(750\right.$ to $\left.4400 \mathrm{~cm}^{-1}\right)$ with a spectral resolution of $0.02 \mathrm{~cm}^{-1}$. The satellite orbits at $650 \mathrm{~km}$ at an inclination of $74^{\circ}$. The instrument uses solar occultations to scan the atmosphere at sunrise and sunset each orbit, restricting the measurements to a particular latitude range per day. It is, however, one of the longest running experiments and contributes 1941 measurement days from 10 January 2004 until 30 September 2010 to this comparison. The ACE-FTS measurements are made every $2 \mathrm{~s}$, which corresponds to a vertical spacing of $2-6 \mathrm{~km}$ (depending on beta angle). The vertical resolution of ACE-FTS is about $3 \mathrm{~km}$ based on the instrument field of view of $1.25 \mathrm{mrad}$.

ACE-FTS retrievals of NO use 36 microwindows between 5.18 and $5.43 \mu \mathrm{m}, 19$ of which are focussed on the higher altitude ranges. The non-linear least-squares fitting scheme used for ACE-FTS is described in Boone et al. (2005). Here we use version 3.0 of the retrievals which extend from about 6 to $107 \mathrm{~km}$ (Boone et al., 2013). The previous version of the ACE-FTS NO product (version 2.2+updates) has been compared with HALOE profiles where differences of up to $+10 \%$ are found between 93 and $105 \mathrm{~km}$ (Kerzenmacher et al., 2008). Compared to version $2.2+$ updates, version 3.0 NO profiles are smaller by about $2 \%$ above $40 \mathrm{~km}$ (Waymark et al., 2013). The ACE-FTS profiles are provided in two formats: on the measurement tangent grid and interpolated onto a uniform $1 \mathrm{~km}$ grid (using the piecewise quadratic technique). In this study, we use the sunrise data on the uniform $1 \mathrm{~km}$ grid.

\subsection{Odin/SMR}

Odin is a Swedish-led satellite, in cooperation with the Canadian, French and Finnish space agencies (Murtagh et al., 2002; Nordh et al., 2003). It was launched in February 2001 and became a European Space Agency (ESA) third-party mission in 2007. This satellite is orbiting the Earth in a sunsynchronous orbit, at an initial altitude of $580 \mathrm{~km}$ and varying Equator-crossing times between 06:00 and 07:00, and 18:00 and 19:00 local time. These parameters are slightly changing with time due to the drifting orbit. Odin was initially a joint astronomy and aeronomy mission, and before 2007 the observation time was equally divided between the two disci- 
plines. The satellite is now entirely dedicated to atmospheric measurements.

SMR is one of the instruments on board this satellite. It is a limb emission sounder measuring globally a variety of trace gases and the temperature in the whole middle atmosphere. SMR uses four sub-millimetre channels (486.1$503.9,541.0-558.0,547.0-564.0,563.0-581.4 \mathrm{GHz})$ and one millimetre-wave channel $(118.25-119.25 \mathrm{GHz})$ (Merino et al., 2002). The observation of different species requires channel switching. Nitric oxide is retrieved from the observation of thermal emission lines in a band centred around $551.7 \mathrm{GHz}$ (Urban et al., 2007; Sheese et al., 2013). In the case of SMR, $\log (\mathrm{VMR})$ is retrieved. This possibly leads to a positive bias, but only at middle to low latitudes below $85 \mathrm{~km}$, where the SMR sensitivity to NO is low in general. Systematic errors amount to $3 \%$ from spectroscopic parameters, $2 \%$ from calibration, and 3-6\% from sideband suppression (Sheese et al., 2013). The overall vertical coverage is from 7 to $115 \mathrm{~km}$, and in the altitude range considered here the vertical resolution is about $7 \mathrm{~km}$ (Pérot et al., 2014). The retrieval error in Antarctic night MLT NO amounts to 44$48 \%$ (Sheese et al., 2013).

We use the data version 2.1 in this study, and SMR contributes NO observations on 301 days from 7 October 2003 to 25 December 2012, with about 600 scans per day.

\subsection{Data preparation}

The individual measurements of nitric oxide (NO) from each instrument were averaged to daily zonal mean values binned into $5^{\circ}$ latitude bins. In the vertical direction, no additional interpolation was done for the MIPAS and SCIAMACHY data, and the fixed retrieval altitude grids were used. The SMR data were retrieved on the tangent altitude grid, profile by profile, interpolated onto a fine altitude grid, followed by averaging in $5^{\circ}$ latitude bins on each level. As mentioned in Sect. 2.3, the ACE-FTS data on the interpolated $1 \mathrm{~km}$ grid were used in this study.

To prepare these data, volume mixing ratios had to be converted to number densities. The ACE-FTS VMRs were converted to number density using the density from the simultaneously retrieved temperatures (Boone et al., 2005). The MIPAS data, which were retrieved as $\log (\mathrm{VMR})$, were also converted using the simultaneously retrieved temperatures (Funke et al., 2005; Bermejo-Pantaleón et al., 2011). The SMR data were also retrieved as $\log (\mathrm{VMR})$ using ECMWF analyses and CIRA temperature fields above $70 \mathrm{~km}$ (Barnett and Corney, 1985). The mixing ratios were converted to number densities using the same temperatures. Note that we only use the daytime (a.m.) data versions from MIPAS and SMR and the sunrise data from ACE-FTS in this study.

The averaged data were additionally filtered by the sensitivity of the instruments. The ACE-FTS measurements have been filtered based on the Data Issues List (https://databace.scisat.ca/validation/data_issues.php) to remove profiles marked as "do not use". The MIPAS and SCIAMACHY data are filtered based on the average diagonal element of the averaging kernel matrix. The thresholds are 0.003 for MIPAS and 0.01 for SCIAMACHY. The SMR data are filtered using the measurement response, which is the sum of the rows of the averaging kernel matrix. All zonal mean boxes with a mean measurement response below 0.75 were not considered.

\section{Zonal mean data}

Figures 1 and 2 show the zonal mean data at altitudes of 85 and $105 \mathrm{~km}$ from all instruments: ACE-FTS, MIPAS, SCIAMACHY, and SMR. The zonal mean data at additional altitudes from 75 to $115 \mathrm{~km}$ are shown in Appendix A in Figs. A1 to A5.

These figures give an overview of the available data set. ACE-FTS, as a solar occultation instrument, has only limited geographical coverage. MIPAS and SMR have limited sensitivity at altitudes below $85 \mathrm{~km}$, in particular at middle and low latitudes. Additionally, MIPAS data from 75 to $100 \mathrm{~km}$ are at present only available from July 2008. The SCIAMACHY data are restricted to daytime measurements, which adversely affects the number of measurements, in particular at high latitudes in the polar winter. SMR data are relatively sparse before 2007, when the Odin astronomy mission ended, and more measurement days have been dedicated to NO observations since then.

The zonal mean data of all four instruments are consistent with respect to the annual variation of the NO density in the MLT region. Throughout the latitude range, the number densities are low at times of low solar activity, 2008 and 2009, and increase with growing solar activity, 2010 and 2011. The NO density increases most in the polar regions and at higher altitudes. Between 95 and $115 \mathrm{~km}$, the density increases also at lower latitudes, in particular after 2011.

\section{Time series}

To put the comparisons from Sect. 3 onto more quantitative grounds, we directly compare the NO density time series in four different $5^{\circ}$ latitude bins and at altitudes from 75 to $115 \mathrm{~km}$. These bins are located at high northern $\left(67.5^{\circ} \mathrm{N}\right)$ and high southern latitudes $\left(67.5^{\circ} \mathrm{S}\right)$, at middle latitudes $\left(32.5^{\circ} \mathrm{S}\right)$, and at low latitudes $\left(2.5^{\circ} \mathrm{N}\right)$ near the Equator.

\subsection{Northern Hemisphere}

We first compare the values in the Northern Hemisphere at $67.5^{\circ} \mathrm{N}$. Figure 3 shows the time series at two example altitudes, $85 \mathrm{~km}$ (upper mesosphere) and $105 \mathrm{~km}$ (lower thermosphere). Figure B1 in Appendix B shows the time series at more altitudes from 75 to $115 \mathrm{~km}$. 
Table 1. Instrument overview

\begin{tabular}{llllc}
\hline & SCISAT & Odin & & Envisat \\
& ACE-FTS & SMR & MIPAS & SCIAMACHY \\
\hline Orbit & & Sun synchronous & & Sun synchronous \\
Altitude & $650 \mathrm{~km}$ & $580 \mathrm{~km}$ & & $790 \mathrm{~km}$ \\
Equator-crossing time & Variable & $06: 00-07: 00 / 18: 00-19: 00$ & & $10: 00 / 22: 00$ \\
Measurement type & Solar occultation & Limb & Limb & Limb \\
NO wavelength & Infrared & Sub-mm & Infrared & Ultraviolet \\
Vertical resolution $(\mathrm{km})$ & $\approx 3$ & $\approx 7$ & $5-20$ & $5-10$ \\
MLT measurement days & 1941 & 301 & 199 & 78 \\
MLT time period & $2004-2010$ & $2003-$ present & $2005-2012$ & $2008-2012$ \\
Data version & 3.0 & 2.1 & V40 (2005-2009) & 2.0 \\
& & & V5R (2010-2012) \\
\hline
\end{tabular}

Table 2. Uncertainty estimates; see text for details.

\begin{tabular}{lllll}
\hline & ACE-FTS & SMR & MIPAS & SCIAMACHY \\
\hline Measurement noise error & NA & NA & $\begin{array}{l}30-50 \% \text { below } 100 \mathrm{~km} \\
10-50 \% \text { above } 100 \mathrm{~km}\end{array}$ & $30 \%$ \\
Systematic error & $93-105 \mathrm{~km}:$ & $10 \%$ & $5-10 \%$ & $10-20 \%$ \\
& $+10 \%$ vs HALOE & & Above $120 \mathrm{~km}:$ \\
& & Up to $50 \%$ (atomic oxygen) & \\
\hline
\end{tabular}

The results are consistent throughout the altitude range; the largest values are observed between 95 and $105 \mathrm{~km}$, and smaller values below and above these altitudes. Only SMR and ACE-FTS provide data below $100 \mathrm{~km}$ for the years 2004 to 2008 . Above $100 \mathrm{~km}$, MIPAS contributes some data points from 2005 onwards, and SCIAMACHY data are available only from the mid-2008.

ACE-FTS, SMR, and MIPAS show that the NO number density is correlated with solar activity. From 2004 to 2007, a period of moderate solar activity, the number densities were generally larger than in $2008 / 2009$, when solar activity was low. The NO density increases then again after 2009 with the onset of the next solar cycle. This correlation is visible at all altitudes, and it is particularly strong in the main production region from 95 to $105 \mathrm{~km}$. Unfortunately, the SCIAMACHY data set is too short to show the same correlation. The SCIAMACHY number densities are always on the low side compared to the other instruments. This is less pronounced at $75 \mathrm{~km}$ but is clearly visible at altitudes of $85 \mathrm{~km}$ and above.

In addition to the overall correlation of the NO densities with the long-term solar activity, the seasonal cycle is clearly visible in the data from all instruments. This annual variation is more pronounced at $85 \mathrm{~km}$, but it is also visible at $105 \mathrm{~km}$.

\subsection{Southern Hemisphere}

Figure B2 in Appendix B shows the NO number density at $67.5^{\circ} \mathrm{S}$ from 75 and $115 \mathrm{~km}$. The values agree at the same level as in the Northern Hemisphere, and the density responds similarly to solar activity.
The annual cycle is also visible in all data sets, as it is in the Northern Hemisphere. Again, this cycle is more pronounced at $85 \mathrm{~km}$ but is also visible at $105 \mathrm{~km}$. The SCIAMACHY data above $95 \mathrm{~km}$ are low compared to the other three instruments but are still within the error range.

\subsection{Middle and low latitudes}

Figure 4 shows the comparisons at middle latitudes $\left(32.5^{\circ} \mathrm{S}\right)$ at 85 and $105 \mathrm{~km}$. The data at all altitudes are shown in Appendix B in Fig. B3. Similarly, the data at $2.5^{\circ} \mathrm{N}$ are compared in the same appendix in Fig. B4 (from 75 to $115 \mathrm{~km}$ ).

In general, the magnitude of the NO number density in these regions is smaller than at higher latitudes by a factor of 5 to 10, in particular at polar winter, as also discussed in Bermejo-Pantaleón et al. (2011). Above $95 \mathrm{~km}$, the SCIAMACHY measurements are low compared to the other instruments, but they are well within the variations of the data.

At altitudes above $95 \mathrm{~km}$, the number densities follow the solar cycle activity. They decline at the beginning and increase again at the end of the investigated period. A distinct annual cycle of the NO density is not clearly identifiable at these latitudes. This is in contrast to the time series at higher latitudes and the result of different production mechanisms depending on latitude. It is already known that, at high latitudes and under auroral conditions, the production of NO is larger than that at equatorial latitudes. The differences between the polar summer and polar winter regions come from larger photochemical losses in the summer, leading to smaller NO densities (Bermejo-Pantaleón et al., 2011). 

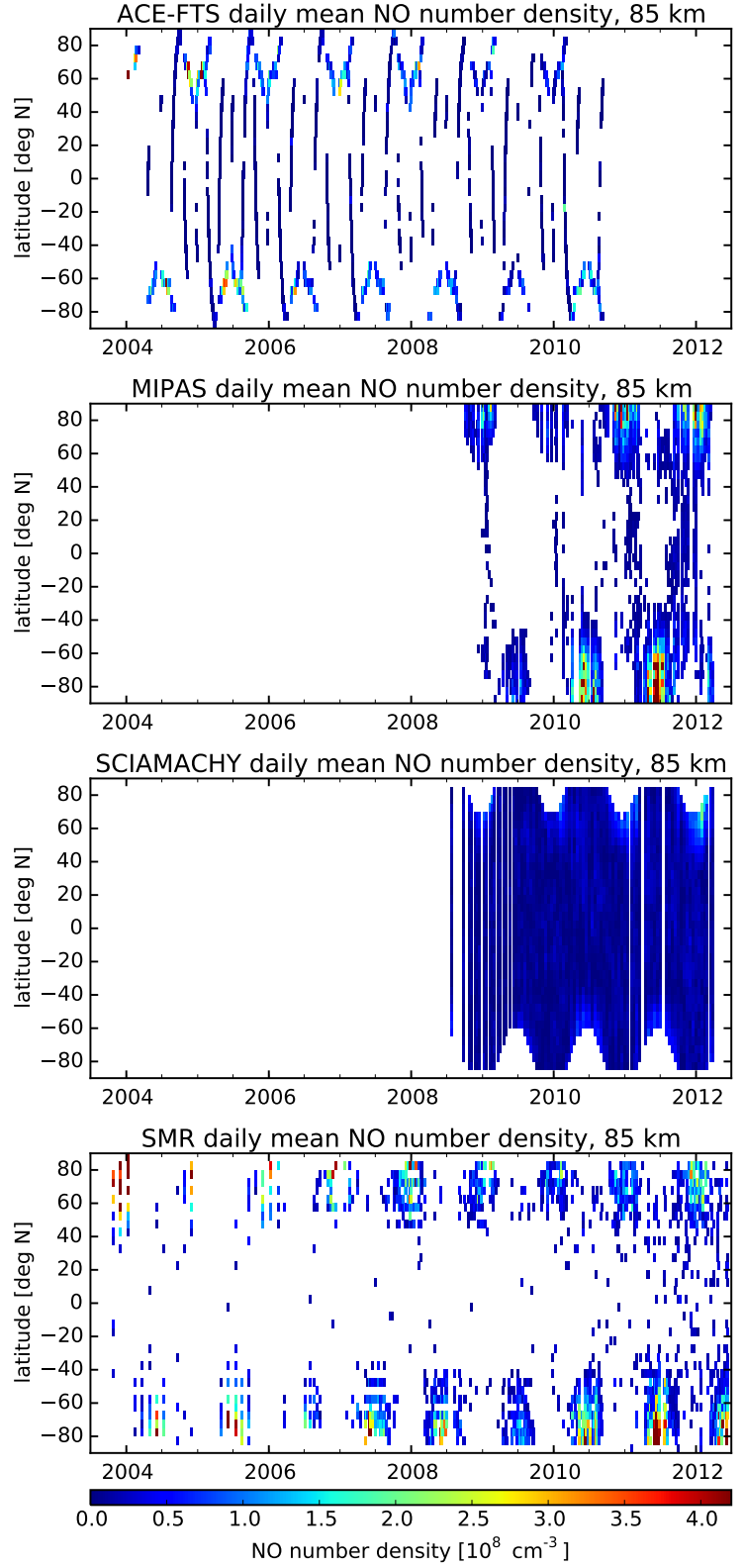

Figure 1. NO zonal mean time series at $85 \mathrm{~km}$ from ACE-FTS, MIPAS, SCIAMACHY, and SMR (from top to bottom).

The time series from all instruments are consistent in all regions we compared, in particular considering the sometimes large error bars (equal to the $95 \%$ confidence interval of the daily zonal mean). Larger differences indicate shortterm variations that are measured by one instrument on a particular day when none of the other instruments observed NO in the upper atmosphere.

The error bars in the figures indicate the statistical error only. Random retrieval errors are most likely much smaller than the natural variability (the latter hence dominating the standard errors of the mean), and biases are very difficult to estimate consistently for all instruments in a bottom-up man-
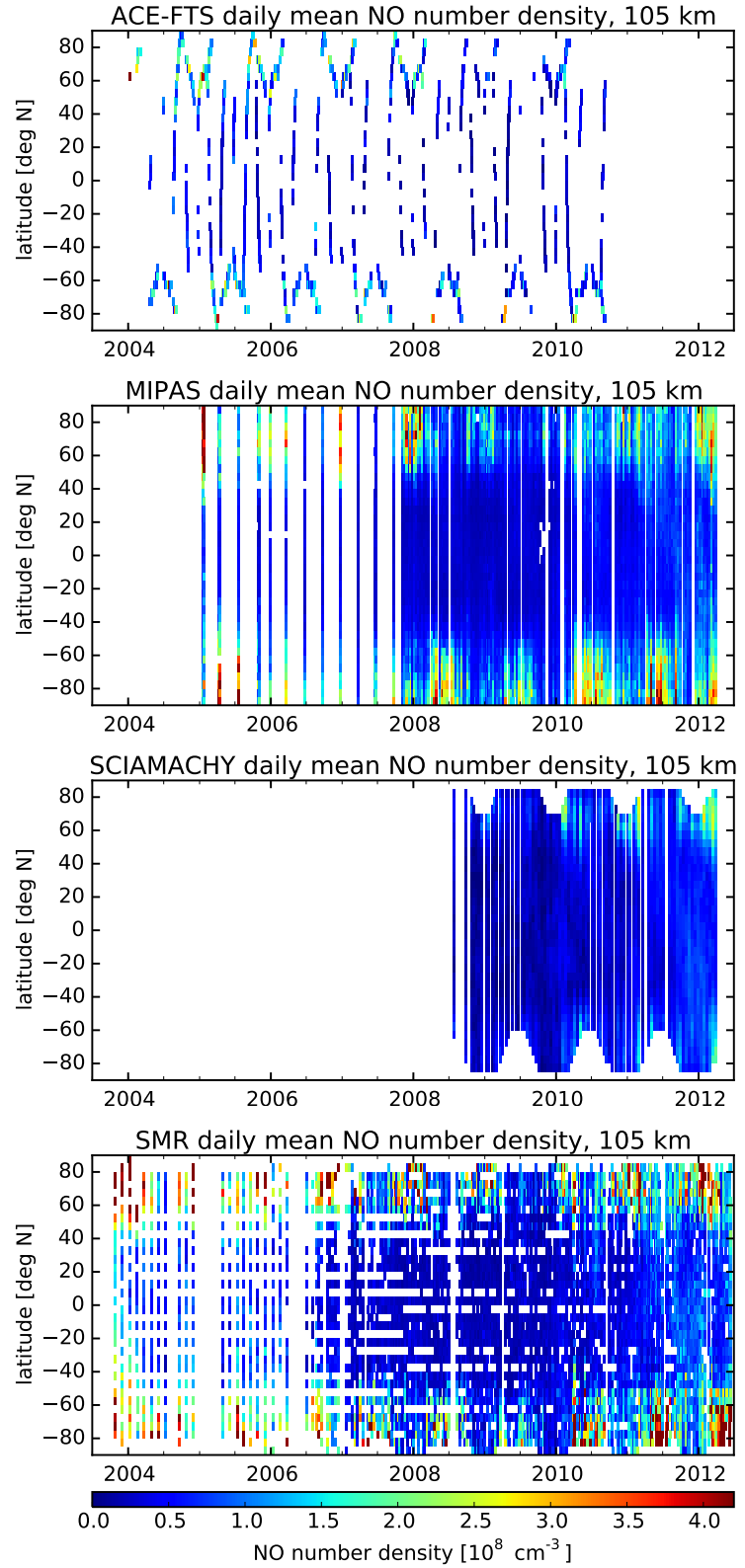

Figure 2. NO zonal mean time series at $105 \mathrm{~km}$ from ACE-FTS, MIPAS, SCIAMACHY, and SMR (from top to bottom).

ner. Here we determine biases between different instruments in a top-down approach.

\section{Vertical profiles}

We obtain the most direct comparison of the individual results by comparing the vertical density profiles. Discrepancies in the profiles provide insight into the characteristic strengths and weaknesses of the individual instruments and their NO retrieval. However, we focus here on daily zonal mean data, and, apart from SCIAMACHY and MIPAS on 


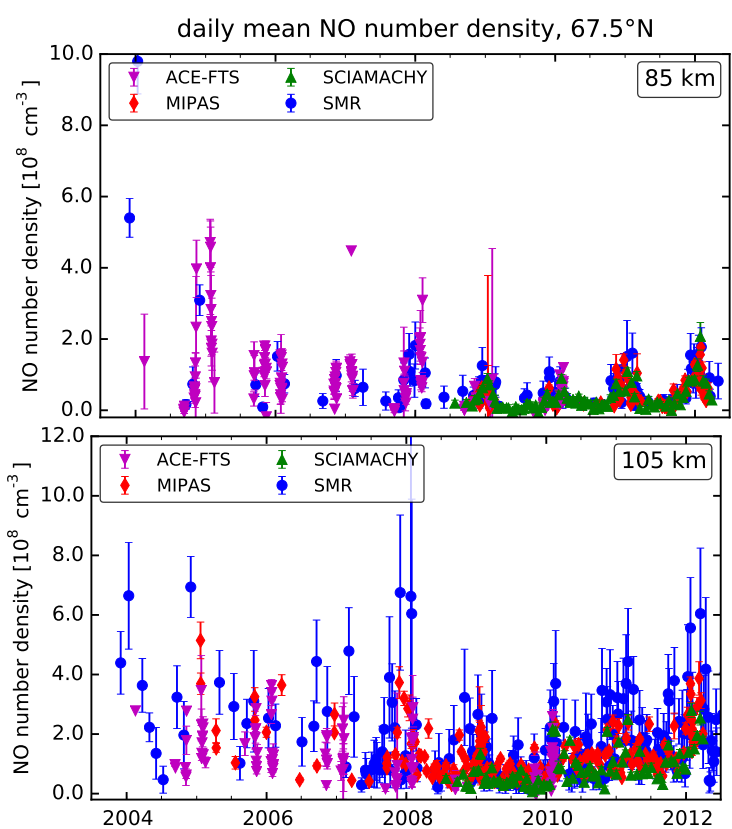

Figure 3. NO time series comparison of all four instruments at $67.5^{\circ} \mathrm{N}$, for $85 \mathrm{~km}$ (top) and $105 \mathrm{~km}$ (bottom). The error bars indicate the statistical $95 \%$ confidence interval of the daily zonal mean.

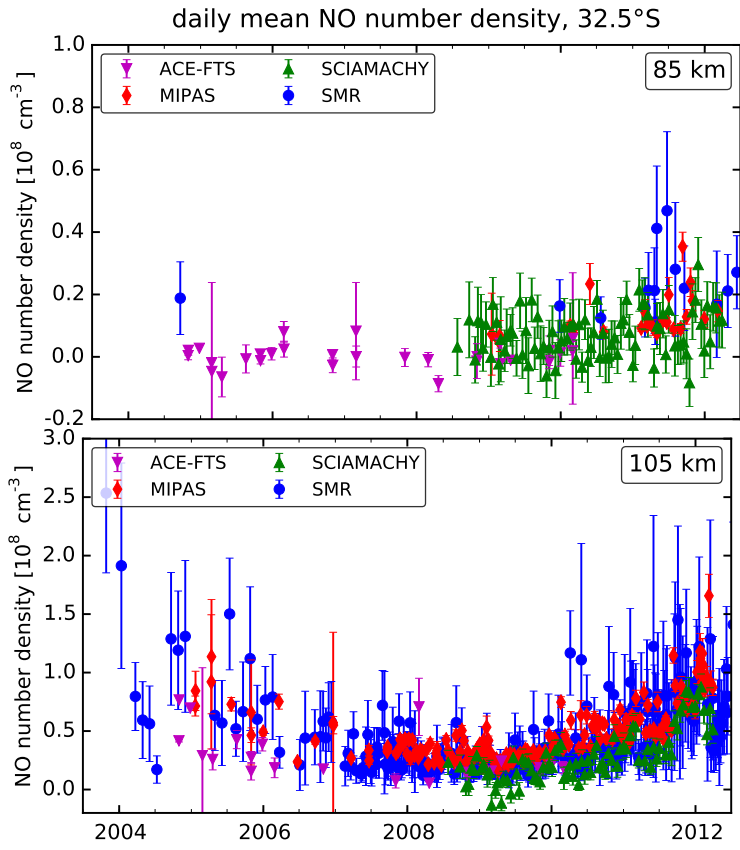

Figure 4. NO time series comparison as in Fig. 3 for $32.5^{\circ} \mathrm{S}$.

the same satellite, the local solar times of the measurements differ substantially. In addition, the different distributions of the individual measurement or tangent points make comparing vertical profiles difficult.

To obtain reliable statistics about the profiles, we first calculate the difference profile for each coincident $5^{\circ}$ latitude

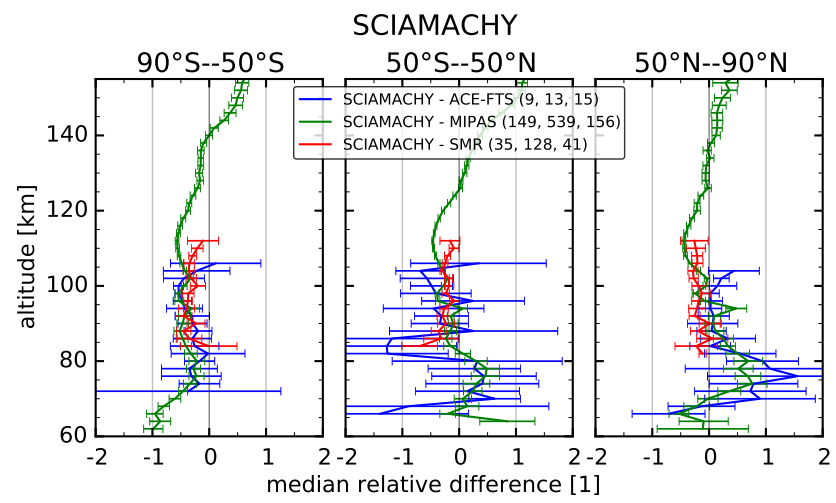

Figure 5. NO vertical profile comparison of the SCIAMACHY NO number density $\left(n_{\mathrm{NO}}^{\mathrm{SCIAMACHY}}\right)$ to the other instruments $\left(n_{\mathrm{NO}}^{\text {other }}\right)$. Shown is the median of the relative differences $\left(n_{\mathrm{NO}}^{\text {SCIAMACHY }}-\right.$ $\left.n_{\mathrm{NO}}^{\text {other }}\right) / n_{\mathrm{NO}}^{\text {other }}$ averaged over days coincident with other observations. The panels show the results in the southern polar region (left), at middle and low latitudes (middle), and in the northern polar region (right). The error bars indicate the $95 \%$ confidence interval using the median absolute deviation $(3 \times \mathrm{MAD})$. The numbers in parentheses denote the number of coincident profiles in these three regions from south (left) to north (right).

bin of two instruments, that is, on days when both instruments provide data in the same bin. These differences are calculated on a common altitude grid; the data are interpolated if necessary. We then take the median of all these difference profiles in three geographical regions: $90-50^{\circ} \mathrm{S}, 50^{\circ} \mathrm{S}-$ $50^{\circ} \mathrm{N}$, and $50-90^{\circ} \mathrm{N}$.

\subsection{SCIAMACHY}

First we compare the SCIAMACHY data to the other instruments because it provides the most regular data throughout the altitude and latitude range (see Figs. 1 and 2). Figure 5 shows the median profile of the relative number density differences between the SCIAMACHY measurements $\left(n_{\mathrm{NO}}^{\mathrm{SCIAMACH}}\right)$ and the other instruments $\left(n_{\mathrm{NO}}^{\text {other }}\right)$, averaged over days coincident with other observations. Shown are the results in the southern polar region $\left(90-50^{\circ} \mathrm{S}\right)$, at middle and low latitudes outside the polar regions $\left(50^{\circ} \mathrm{S}-50^{\circ} \mathrm{N}\right)$, and in the northern polar region $\left(50-90^{\circ} \mathrm{N}\right)$.

MIPAS and SCIAMACHY share the same satellite, and therefore they performed the most congruent measurements. In addition, their limb scans were scheduled to measure the mesosphere and lower thermosphere during the same orbits once a month. Therefore, we get the best statistics from this pair of instruments.

SCIAMACHY has fewer coincident days with SMR than with MIPAS. We also have to consider the different local times of the measurements, which are 10:00 for SCIAMACHY and between 06:00 and 07:00 for SMR (at the equator). This timing of the SMR measurements makes them susceptible to the NO diurnal cycle and may lead to systematic 
differences in the measured number densities, in particular in the lower mesosphere. The coincidences with ACE-FTS amount to only about 10 to 20 usable profiles. Since ACEFTS measures at sunrise and sunset primarily at higher latitudes, the NO diurnal cycle also affects the retrieved number densities.

The patterns of the MIPAS to SCIAMACHY differences in Fig. 5 are similar in all three regions. The magnitude of the difference varies slightly with the region; it is smallest at middle and low latitudes and at high northern latitudes. Between 120 and $140 \mathrm{~km}$, the MIPAS and SCIAMACHY number densities agree well in all three regions; the SCIAMACHY NO densities differ only slightly from the MIPAS measured densities. In the main production region from 100 to $120 \mathrm{~km}$, SCIAMACHY significantly underestimates the NO number densities compared to MIPAS measurements by about $50 \%$ at high southern latitudes and by about $40 \%$ at middle and low latitudes and at high northern latitudes. Between 70 and $95 \mathrm{~km}$ in the northern polar region, the SCIAMACHY NO number densities are larger than the measurements from ACE-FTS and MIPAS. The SCIAMACHY data are consistent with the other instruments at these altitudes in the southern polar region and at middle and low latitudes.

SCIAMACHY consistently measures smaller number densities than SMR by 10 to $20 \%$. The data agree from 80 to $100 \mathrm{~km}$ in the northern polar region. At middle and low latitudes, the SCIAMACHY and SMR densities agree at $95 \mathrm{~km}$ and at $110 \mathrm{~km}$.

The SCIAMACHY data agree well with the ACE-FTS data in the Northern Hemisphere. In the Southern Hemisphere, the SCIAMACHY measurements are smaller than the ACE-FTS number densities between 90 and $105 \mathrm{~km}$. Both number densities are consistent below $90 \mathrm{~km}$ considering the statistical error. At middle and low latitudes the instruments agree within the large error range.

\subsection{Other instruments}

Figure 6 shows the median of the relative differences comparing MIPAS data to the other instruments.

In all three regions, MIPAS measures the largest NO number densities between 100 and $120 \mathrm{~km}$, between 80 and $120 \%$ larger than measured by the other instruments. As seen in the previous section, MIPAS and SCIAMACHY data agree in all three latitude regions at altitudes between 120 and $140 \mathrm{~km}$. Above about $140 \mathrm{~km}$, MIPAS densities are consistently smaller than SCIAMACHY densities, up to $50 \%$ at around $155 \mathrm{~km}$. However, they are still consistent considering the uncertainty of the MIPAS NO densities because of the uncertain amount of atomic oxygen used in the MIPAS retrieval (Bermejo-Pantaleón et al., 2011); see also Table 2. In the northern polar region and at middle and low latitudes, the results agree also between 80 and $95 \mathrm{~km}$. In the southern polar region, the MIPAS measurements are about 50 to

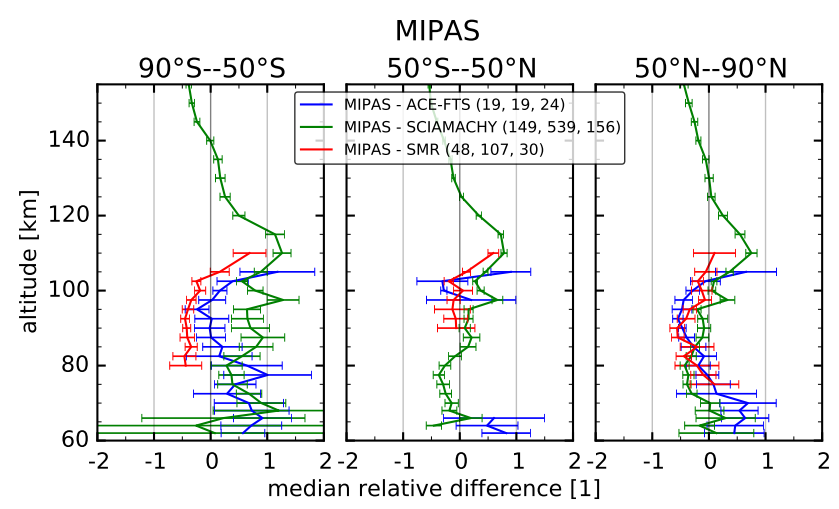

Figure 6. NO vertical profile comparison of MIPAS NO data $n_{\mathrm{NO}}^{\text {MIPAS }}$. For a detailed description see Fig. 5.

$100 \%$ larger than the SCIAMACHY measurements from 70 to $95 \mathrm{~km}$.

Between 80 and $100 \mathrm{~km}$ in the southern polar region, the MIPAS and the ACE-FTS data agree well. Below $80 \mathrm{~km}$ and above $100 \mathrm{~km}$, in this region, the MIPAS number densities are larger by 50 to $100 \%$. At middle and low latitudes MIPAS and ACE-FTS have only a few coincident measurement days and even fewer comparable data points when considering the instruments' sensitivity. In the upper usable altitude region, between 95 and $105 \mathrm{~km}$, MIPAS and ACE-FTS are consistent. In the lower altitude region from 65 to $70 \mathrm{~km}$, MIPAS number densities are larger by 50 to $80 \%$. In the northern polar region, the MIPAS number densities are also larger than the ACE-FTS measurements in the same altitude region. They are smaller than the ACE-FTS number densities between 85 and $100 \mathrm{~km}$.

Compared to SMR, the MIPAS NO number densities are significantly smaller in the southern polar region from 80 to $100 \mathrm{~km}$ by about 40 to $50 \%$. In the northern polar region from 80 to $100 \mathrm{~km}$, the MIPAS number densities are about 30 to $50 \%$ smaller than the SMR data. Above and below, MIPAS and SMR agree within the statistical error. The number densities of each agree well at middle and low latitudes between 90 and $100 \mathrm{~km}$.

Figure 7 shows the median of the relative profile differences comparing the SMR data to the other measurements.

In all three regions, the SMR number densities are consistently larger than the SCIAMACHY data above $100 \mathrm{~km}$. We observe the largest differences in the southern polar region, up to $80 \%$. However, the number densities of each agree in the northern polar region from 80 to $100 \mathrm{~km}$. At middle and low latitudes, the difference between SMR and SCIAMACHY vary between 10 and $40 \%$, reaching larger but insignificant values between 85 and $90 \mathrm{~km}$.

Compared to MIPAS, the SMR number densities are significantly smaller in all three regions from 100 to $120 \mathrm{~km}$ by 20 to $50 \%$. From 85 to $100 \mathrm{~km}$, the SMR number densities are consistently larger than the MIPAS data, in the southern 


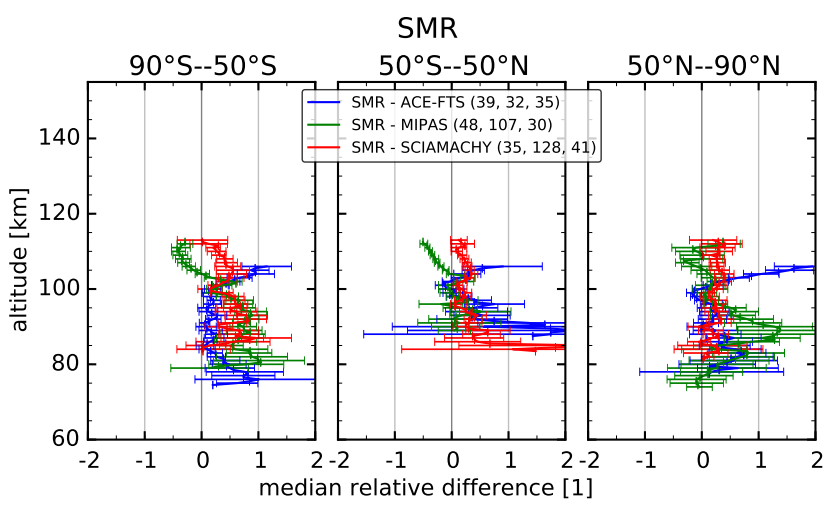

Figure 7. NO vertical profile comparison of the SMR data $n_{\mathrm{NO}}^{\mathrm{SMR}}$. See Fig. 5 for details.

polar region between 50 and $80 \%$, and in the northern polar region up to $120 \%$ but with a large uncertainty. At middle and low latitudes, both measurements are consistent between 90 and $105 \mathrm{~km}$.

Compared to ACE-FTS, the SMR number densities are substantially larger at high southern latitudes above $100 \mathrm{~km}$, differing by $100 \%$ at $105 \mathrm{~km}$. ACE-FTS and SMR data agree well between 80 and $100 \mathrm{~km}$. Below $80 \mathrm{~km}$ in that region, the SMR number densities differ from the ACE-FTS results between 50 and $80 \%$ but with a large statistical uncertainty. The NO number densities are comparable at middle and low latitudes over the whole altitude range, considering the statistics. The differences in the northern polar region behave similarly to the results at high southern latitudes; the maximum deviation is $150 \%$ at $105 \mathrm{~km}$. Here, the two data sets agree well between 90 and $100 \mathrm{~km}$. The SMR number densities are up to $60 \%$ larger than the ACE-FTS data below $90 \mathrm{~km}$ in that region.

Figure 8 shows the median of the relative profile differences of the ACE-FTS NO number densities to the other instruments. It summarises the above discussion from ACEFTS' point of view, showing the best agreement with MIPAS and SMR in the southern polar region from 85 to $100 \mathrm{~km}$, and with SCIAMACHY and SMR in the northern polar region from 80 to $100 \mathrm{~km}$. The ACE-FTS number densities are substantially larger than the SCIAMACHY measurements in the southern polar region between 90 and $105 \mathrm{~km}$. They also differ significantly from the MIPAS data in the northern polar region between 85 and $100 \mathrm{~km}$. At middle and low latitudes, the ACE-FTS measurements are smaller than all other number densities from 70 to $100 \mathrm{~km}$ by 40 to $100 \%$.

\subsection{Vertical resolution}

The vertical resolution differs between the instruments; see Sect. 2. Two of them, SCIAMACHY and SMR, have a similar resolution of about $5-10$ and $7 \mathrm{~km}$ respectively. The ACE-FTS vertical resolution lies between 3 and $6 \mathrm{~km}$. Above

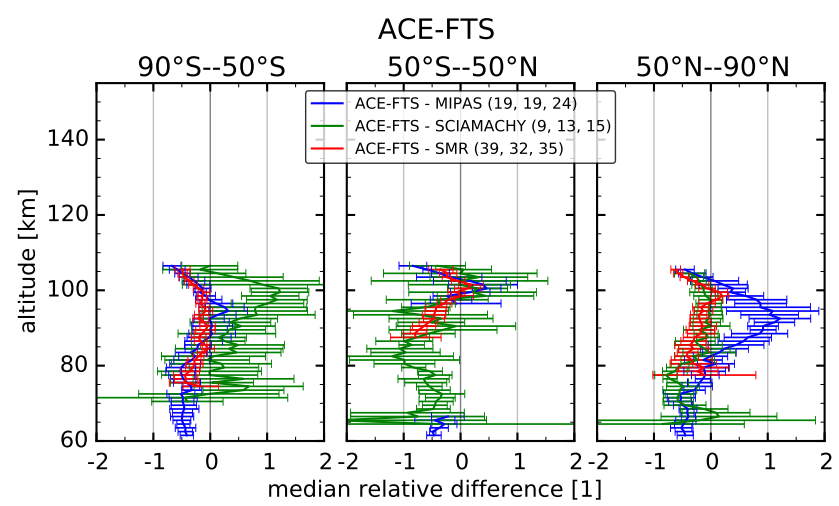

Figure 8. NO vertical profile comparison of the ACE-FTS data $n_{\mathrm{NO}}^{\mathrm{ACE}-\mathrm{FTS}}$. See Fig. 5 for details.

$100 \mathrm{~km}$, MIPAS has the largest range with respect to vertical resolution, between 5 and $10 \mathrm{~km}$ at high geomagnetic activity and between 10 and $20 \mathrm{~km}$ at low geomagnetic activity.

Here we briefly assess the impact of these different resolutions on the daily zonal mean data. In the first case, we apply the SCIAMACHY averaging kernels to the ACEFTS densities. In the second case, we apply the MIPAS upper-atmosphere NO $(100-170 \mathrm{~km})$ averaging kernels to the SCIAMACHY densities.

First we compare ACE-FTS with and without applied SCIAMACHY averaging kernels to each other and to SCIAMACHY. Since the SCIAMACHY retrieval yields number densities, we applied the respective averaging kernels to the ACE-FTS number densities after conversion from VMRs. The medians of the relative differences of the convolved ACE-FTS densities to the original ACE-FTS and SCIAMACHY densities are shown in Fig. 9. This figure also shows the difference between the original ACE-FTS densities and the SCIAMACHY densities as shown in Fig. 8.

We find that at middle and low latitudes the original and convolved ACE-FTS number densities agree within the statistical error of the median. At high northern and southern latitudes, the convolved densities are systematically smaller than the original densities. This improves the agreement between ACE-FTS and SCIAMACHY at high southern latitudes above $90 \mathrm{~km}$, but it adversely affects their consistency at high northern latitudes. The large relative difference at low latitudes between 80 and $88 \mathrm{~km}$ is a result of small number densities measured by ACE-FTS in this region. They are about 1 to 2 orders of magnitude smaller than above and below.

To conclude, we observe an additional high bias of SCIAMACHY compared to the convolved ACE-FTS data at high southern latitudes below $90 \mathrm{~km}$ and at high northern latitudes above $85 \mathrm{~km}$. In almost all regions, the SCIAMACHY number densities are consistently larger than the degraded ACEFTS number densities. 


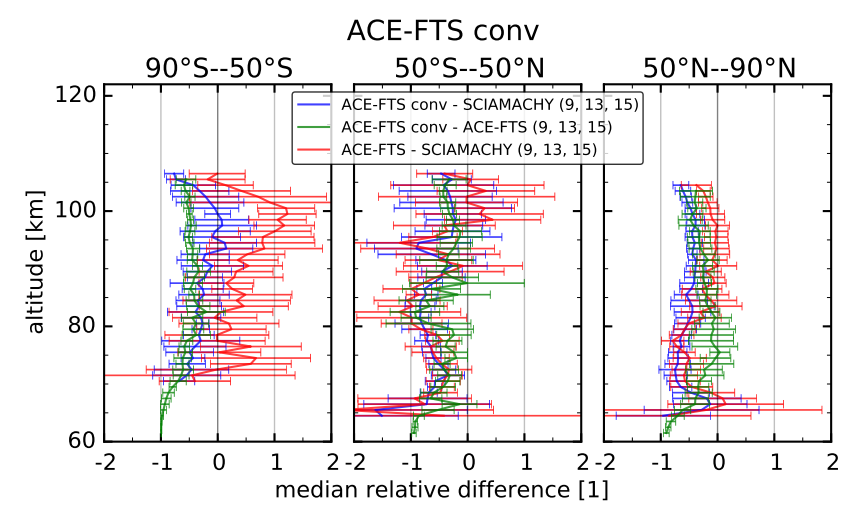

Figure 9. NO vertical difference profile of the convolved ACE-FTS number densities $n_{\mathrm{NO}}^{\text {ACE-FTS conv }}$ compared to the original ACE-FTS data (blue) and to the SCIAMACHY data (green). The difference of the original ACE-FTS densities compared to SCIAMACHY is shown in red.

Next we compare the convolved SCIAMACHY daily zonal mean densities to the original data and to the MIPAS densities whose averaging kernels were applied. Note that we only used 5 days at the end of 2008 for this comparison. The MIPAS V4O upper-atmosphere NO averaging kernels are only defined above $100 \mathrm{~km}$. Thus, they only marginally overlap with ACE-FTS (up to about $107 \mathrm{~km}$ ) and SMR (up to about $115 \mathrm{~km}$ ). Therefore, we only compare SCIAMACHY and MIPAS this way. Furthermore, since the SMR vertical resolution is similar to the SCIAMACHY resolution, the results would be comparable.

The MIPAS upper-atmosphere NO processor retrieves $\log (\mathrm{VMR})$, and, therefore, the averaging kernels have to be applied to $\log (\mathrm{VMR})$. We interpolate the SCIAMACHY data to the MIPAS retrieval grid and use the MIPAS-retrieved pressure and temperature to convert the number densities to VMRs. After applying the MIPAS averaging kernels to the SCIAMACHY VMRs, we convert the volume mixing ratios back to number densities.

The median of the relative differences are shown in Fig. 10. As a reference, the difference of the original SCIAMACHY densities to the same MIPAS V40 upperatmosphere NO data are included as well. Except at high northern latitudes above $130 \mathrm{~km}$, we find that the convolved SCIAMACHY densities are consistently larger than the original SCIAMACHY densities. This indicates a MIPAS high bias related to the coarser vertical resolution. At middle and low latitudes, the difference is small above $125 \mathrm{~km}$, less than $2 \times 10^{7} \mathrm{~cm}^{-3}$, or $50 \%$ of the SCIAMACHY density. However, the difference increases strongly to $100 \mathrm{~km}$, reaching more than $5 \times 10^{7} \mathrm{~cm}^{-3}$, or $100 \%$ of the SCIAMACHY number density.

The original and degraded SCIAMACHY densities agree within the statistical error at high latitudes above about $135 \mathrm{~km}$. Between 135 and $120 \mathrm{~km}$ at high northern latitudes, the original and convolved SCIAMACHY profiles agree. In

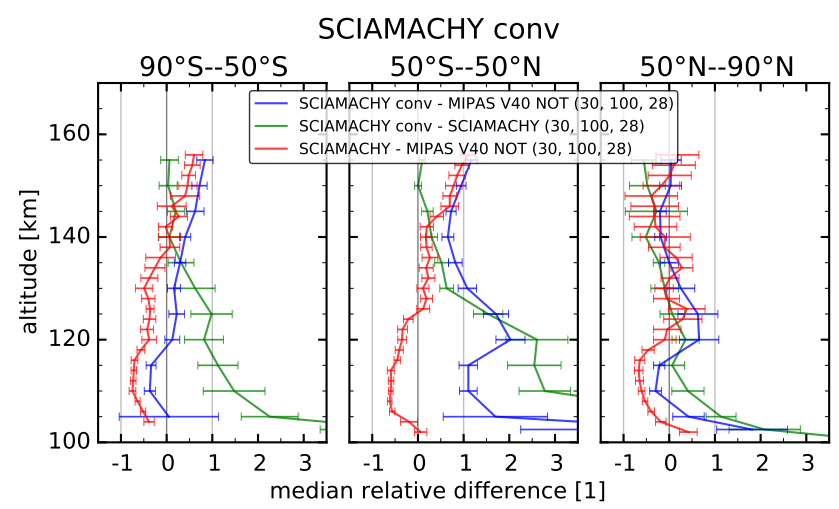

Figure 10. NO vertical difference profile of the convolved SCIAMACHY densities $n$ SC upper-atmosphere NO densities (blue) and to the original SCIAMACHY data (green). We also include the difference of the original SCIAMACHY densities compared to MIPAS (red).

this region, they differ by less than $2 \times 10^{7} \mathrm{~cm}^{-3}$, which is less than $50 \%$ of the original SCIAMACHY profile. The original and convolved SCIAMACHY densities diverge below $135 \mathrm{~km}$ at middle and low latitudes and high southern latitudes. Below $120 \mathrm{~km}$, the difference between the convolved and original profile increases to more than $5 \times 10^{7} \mathrm{~cm}^{-3}$ (nearly $100 \%$ ) at $100 \mathrm{~km}$, indicating a high bias of the MIPAS observations due to the limited vertical resolution there.

The low vertical resolution of MIPAS between 100 and $110 \mathrm{~km}$ is also indicated by a maximum in the width of the averaging kernel functions shown in Bermejo-Pantaleón et al. (2011). Our analysis suggests that this low resolution could introduce a high bias larger than $5 \times 10^{7} \mathrm{~cm}^{-3}$ in the case of strong vertical VMR gradients.

\subsection{Diurnal variations}

Diurnal variations play a role when comparing measurements at different local times. At $106 \mathrm{~km}$ and $65^{\circ}$ latitude (and only there), Bailey et al. (2002) modelled the diurnal variation of NO with a purely chemical model. The differences between the early morning maximum and the evening minimum were found to be about $33 \%$ around the equinoxes. The difference between the morning maximum and noon minimum around winter solstice amounts to about $13 \%$, and it was found to be negligible around summer solstice.

Diurnal variations were also investigated by BermejoPantaleón et al. (2011) using MIPAS a.m./p.m. (10:00/22:00) data. They found up to $140 \%$ larger values at daytime compared to night-time densities at low and middle latitudes in the middle thermosphere (above 120-130 km). At lower altitudes and in particular at higher latitudes, the night-time NO is enhanced by up to $50 \%$ compared to daytime. Below (70$100 \mathrm{~km}$ ), day and night differences are expected to be small since NO is controlled dynamically. 
One would expect that the diurnal variations distinguish in particular the SMR measurements at early morning local time (06:00) and the ACE-FTS measurements at sunrise from the MIPAS and SCIAMACHY measurements at early noon local time (10:00). According to Bailey et al. (2002) and Bermejo-Pantaleón et al. (2011), these early morning measurements should result in larger number densities measured by ACE-FTS and SMR compared to MIPAS and SCIAMACHY. We observe this slight low bias of MIPAS only at high northern latitudes between 90 and $100 \mathrm{~km}$, where the MIPAS number densities are smaller than the ACE-FTS and SMR densities by about 40-50\%; see Figs. 6-8. We find similar behaviour at high southern latitudes but only between MIPAS and SMR between 80 and $100 \mathrm{~km}$. There, ACE-FTS and MIPAS agree well, and SCIAMACHY always shows smaller densities compared to the other three instruments.

Furthermore, at low latitudes $\left(30^{\circ} \mathrm{S}-30^{\circ} \mathrm{N}\right)$, tidal variations were found to impact the diurnal $\mathrm{NO}$ variations in the lower thermosphere (100 to $110 \mathrm{~km}$ ) (Marsh and Russell, 2000; Oberheide and Forbes, 2008). One of these effects, non-migrating tides as discussed by Oberheide and Forbes (2008), induces longitudinal variations of the NO density which cancel in the daily zonal means. Tidal variations should lead to differences when comparing MIPAS or SCIAMACHY measurements to the SMR or ACE-FTS measurements at low latitudes. However, while large relative tidal variations were found, the NO number density at these latitudes is low, and absolute variations are presumably small compared to polar latitudes. At middle and low latitudes, we find no consistent difference between the early morning measurements (ACE-FTS and SMR) and the early noon measurements (MIPAS and SCIAMACHY). This indicates that tidal variations are not the main reason for the observed differences.

\section{Multi-linear regression analysis}

The direct quantitative comparison of the NO data of the four instruments is difficult for several reasons. Coincident measurements are sparse and the local times of the individual measurements differ substantially between some of the instruments. The solar UV radiation influences the NO density annually because of the different solar inclination, and interannually due to its varying intensity during the 11-year solar cycle. Thus, the NO density can vary substantially from day to day depending on particle precipitation rates, for example at times of high geomagnetic activity.

All instruments scanned the MLT region only on particular single days, for example MIPAS every 10 days and SCIAMACHY every 14 days. In addition, the MIPAS and SCIAMACHY data are only available for the later part of the time period. This makes capturing all variations of NO in the upper atmosphere difficult. To overcome these shortcomings, we carry out a multi-linear regression analysis of the zonal mean data.

\subsection{Method}

We construct a simple transfer function for the NO number density $n_{\mathrm{NO}}$ for our multi-instrument intercomparison on non-coincident days. This function includes an offset as well as annual and semi-annual harmonic terms, and it accounts for the solar cycle activity proportional to the UV Lyman- $\alpha$ flux $(\operatorname{Ly} \alpha)$. It also includes a term for daily NO variations caused by geomagnetic activity using the $\mathrm{Kp}$ index.

The NO number density $n_{\mathrm{NO}}$ at altitude $z$, latitude $\phi$, and time $t$ is described by

$$
\begin{gathered}
n_{\mathrm{NO}}^{\text {model }}(\phi, z, t)=a(\phi, z)+b(\phi, z) \cdot \operatorname{Ly} \alpha(t)+c(\phi, z) \cdot \mathrm{Kp}(t) \\
+\sum_{n=1}^{2}\left[d_{n}(\phi, z) \cos (n \omega t)+e_{n}(\phi, z) \sin (n \omega t)\right] .
\end{gathered}
$$

In the transfer function $1, a$ is the constant offset, $d_{1}$ and $e_{1}$ are the annual cycles, and $d_{2}$ and $e_{2}$ are the semi-annual cycles with $\omega=2 \pi /(365.25 \mathrm{~d})$ and $t$ in days. This approach accounts for both amplitude and phase of the cycles. The coefficients $b$ and $c$ refer to the solar Ly $\alpha$ and the geomagnetic $\mathrm{Kp}$ index. We also tested other parameter sets, e.g., the solar radio flux $f 10.7$ for the solar cycle variations and Ap as a geomagnetic proxy. We found that they did not improve the fit and that the combination Lyman- $\alpha$ and Kp gave the best fits. The Kp index is taken from the Space Physics Interactive Data Resource (SPIDR) database (NGDC and NOAA, 2011) and the Lyman- $\alpha$ index from the LISIRD database (DeLand and Cebula, 2008; DeWolfe et al., 2010; LISIRD Data Systems Group, 2010).

\subsection{Results}

The time series of the measurements, the regression result fitting the data from all instruments simultaneously, and the residuals are shown in Figs. 11 and 12 for 85 and $105 \mathrm{~km}$ at $67.5^{\circ} \mathrm{N}$. The same data at $67.5^{\circ} \mathrm{S}$ are shown in Figs. 13 and 14. The regression results without the residuals at more altitudes $(75$ to $115 \mathrm{~km})$ and at additional latitudes $\left(32.5^{\circ} \mathrm{S}\right.$ and $2.5^{\circ} \mathrm{N}$ ) are shown in Appendix $\mathrm{C}$ in Figs. C1 to $\mathrm{C} 4$.

The solid line in these in the upper panels of these figures is the regression fit using the composite data from all instruments simultaneously. The residuals in the lower panels in these figures indicate that the transfer function 1 captures most but not all variations in the NO data. While at $105 \mathrm{~km}$ the residuals are mostly randomly distributed with some outliers, they show residual patterns at $85 \mathrm{~km}$. Most of the time, the residuals vary around $\pm 1 \times 10^{8} \mathrm{~cm}^{-3}$ at lower altitudes, where the number densities take values between 0 and $6 \times 10^{8} \mathrm{~cm}^{-3}$. At higher altitudes the residuals vary between -2 and $+2 \times 10^{8} \mathrm{~cm}^{-3}$, with the number densities varying between 0 and $8 \times 10^{8} \mathrm{~cm}^{-3}$. 


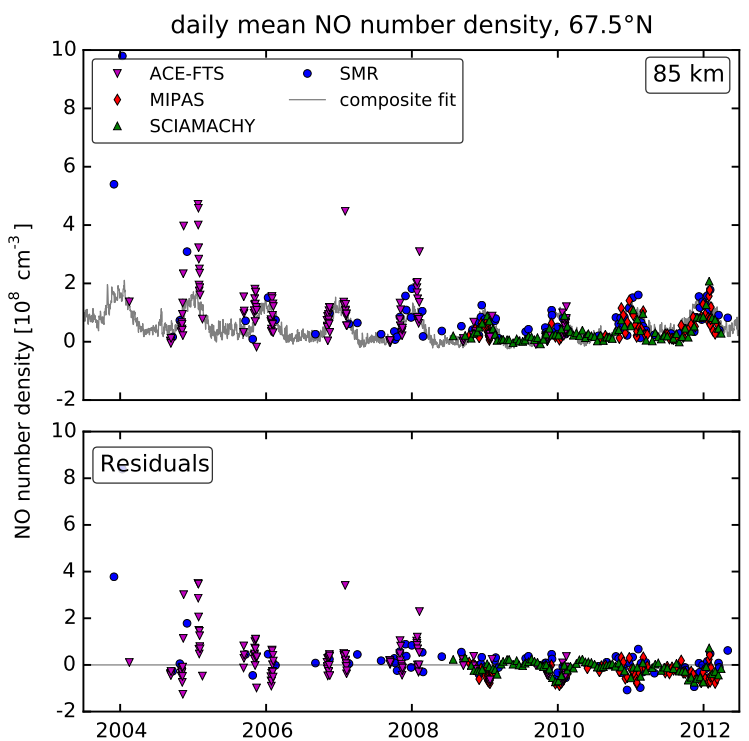

Figure 11. NO time series regression results at $67.5^{\circ} \mathrm{N}, 85 \mathrm{~km}$. The upper panel shows the individual time series and the composite regression fit using all data simultaneously. The lower panel shows the individual residuals with respect to the composite fit.

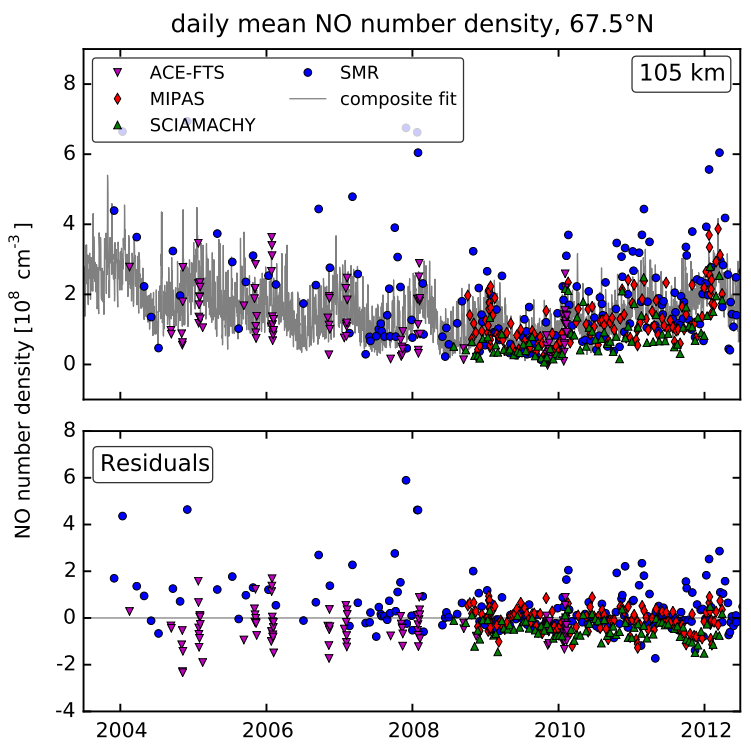

Figure 12. NO time series regression results at $67.5^{\circ} \mathrm{N}, 105 \mathrm{~km}$, as in Fig. 11.

Figure 15 shows the relative mean residuals (RMRs) of the individual measurements to the composite fit. The RMRs are defined as

$\mathrm{RMR}=\frac{\sum_{i}\left(n_{\mathrm{NO}}^{\text {meas }}\left(t_{i}\right)-n_{\mathrm{NO}}^{\text {model }}\left(t_{i}\right)\right)}{\sum_{i} n_{\mathrm{NO}}^{\text {model }}\left(t_{i}\right)}$,

where $n_{\mathrm{NO}}^{\text {meas }}$ and $n_{\mathrm{NO}}^{\text {model }}$ are the measured and modelled NO number densities. Here, modelled data means applying the

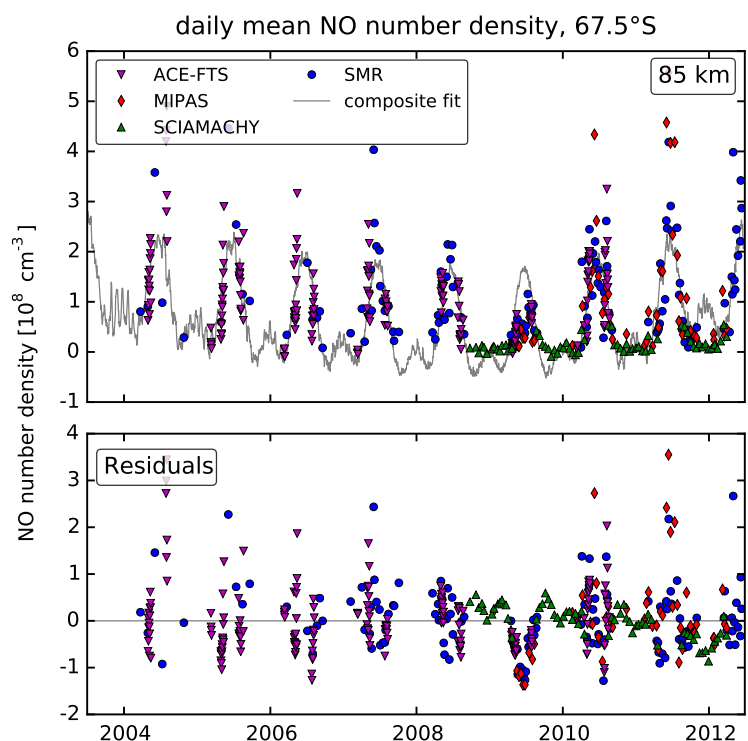

Figure 13. NO time series regression results at $67.5^{\circ} \mathrm{S}, 85 \mathrm{~km}$, as in Fig. 11.

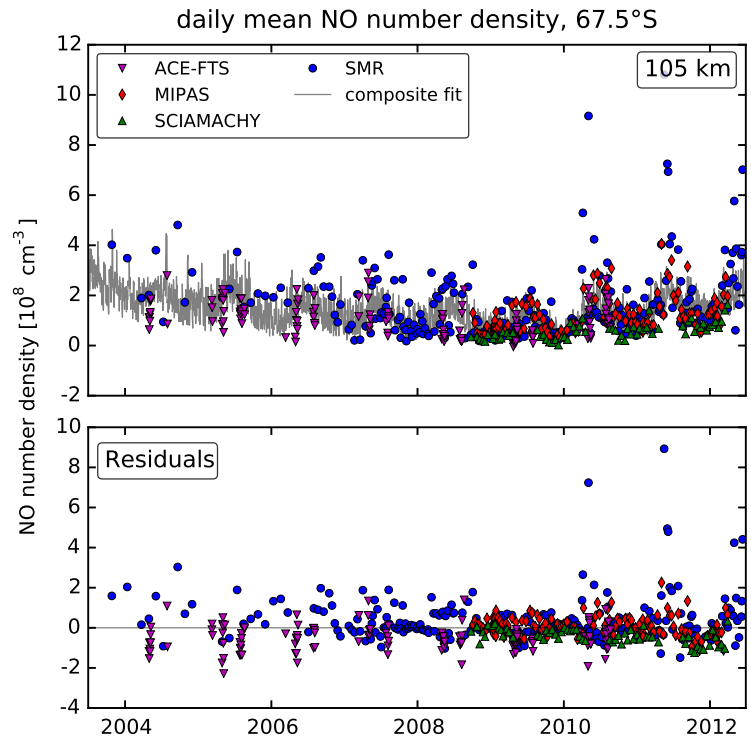

Figure 14. NO time series regression results at $67.5^{\circ} \mathrm{S}, 105 \mathrm{~km}$, as in Fig. 11.

coefficients from the composite fit to the days $t_{i}$ of the individual measurements.

The values shown in Fig. 15 are above the $95 \%$ significance level determined by the $F$ test of the regression fit (Brook and Arnold, 1985; Neter et al., 1996). We find that the ACE-FTS number densities agree with the composite within about $\pm 30 \%$ with only a few large negative values at low latitudes between 80 and $90 \mathrm{~km}$. The MIPAS number densities are consistently larger than the composite fit by about 10 to $30 \%$ above $105 \mathrm{~km}$. Between 70 and $105 \mathrm{~km}$ at middle to high northern latitudes, the MIPAS number den- 

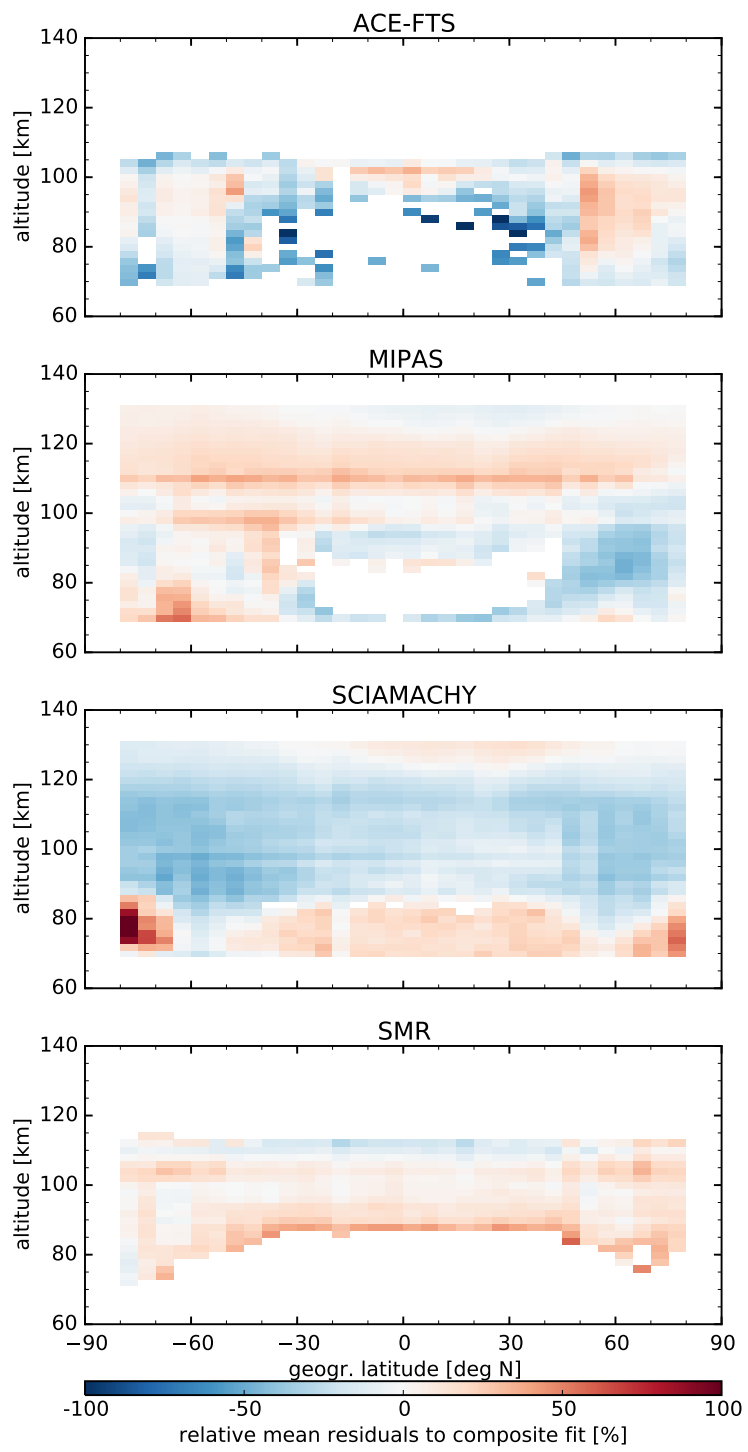

Figure 15. NO mean residuals of the individual measurements to the composite fit. Shown are the values where the regression fit is above the $95 \%$ significance level determined using the $F$ test.

sities are smaller by about the same amount. In the Southern Hemisphere at these altitudes, the MIPAS number densities agree with the composite fit within $\pm 30 \%$. The SCIAMACHY number densities are smaller than the composite fit by about 10 to $30 \%$ above $90 \mathrm{~km}$ throughout the latitude range. They are slightly larger below $90 \mathrm{~km}$, and substantially so between 75 and $85 \mathrm{~km}$ at $77.5^{\circ} \mathrm{S}$. The SMR number densities are larger than the composite fit by about 10 to $20 \%$ almost everywhere, except at the highest altitudes at middle and low latitudes.

We next analyse the coefficients of the individual regressions to compare the instruments' responses to the harmonic cycles and in particular to Lyman- $\alpha$ and Kp changes. Figures 16 and 17 show the cosine coefficients $d_{1}$ and $d_{2}$ of the
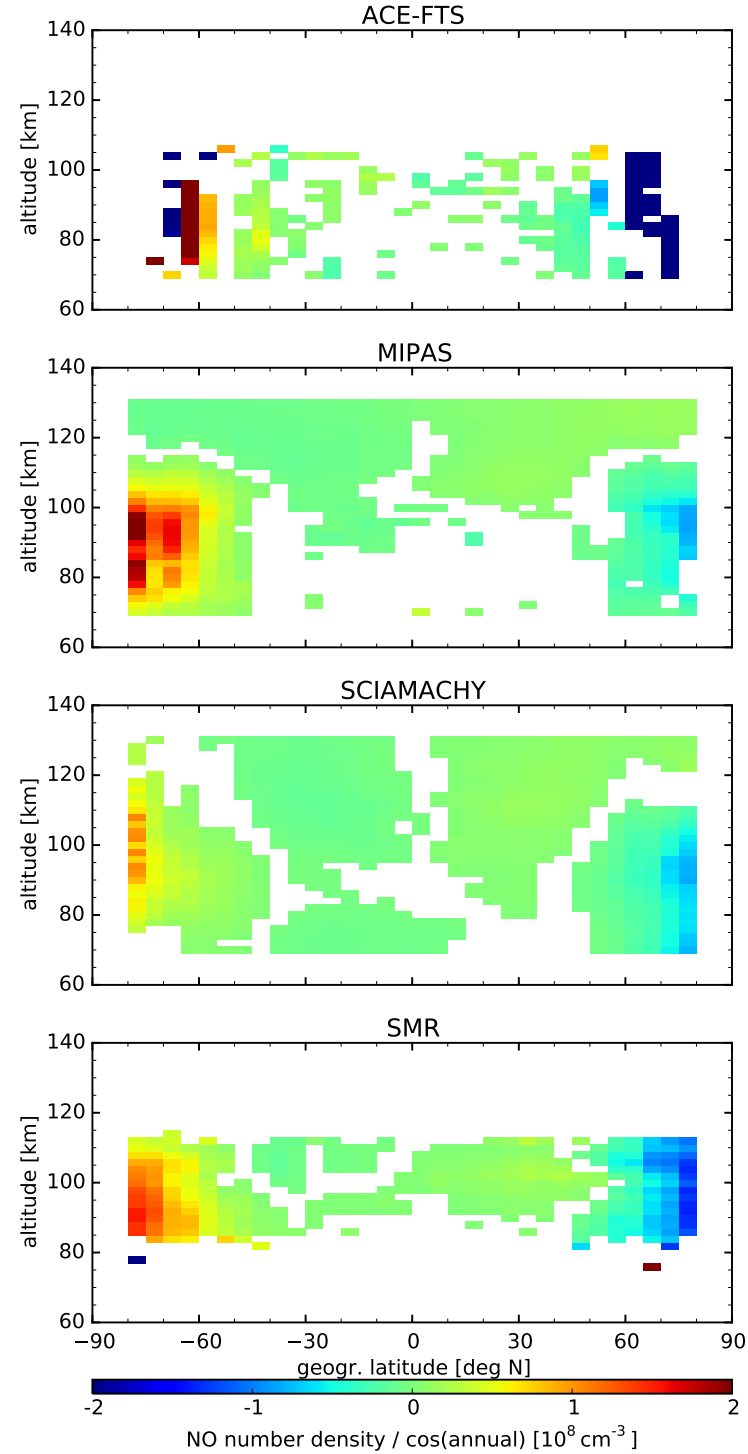

Figure 16. NO regression coefficient $d_{1}$ of the annual cycle (cosine part). Shown are all values above the $95 \%$ significance level of the coefficient calculated using the $t$ test.

annual and semi-annual cycle. Shown are only values with a larger-than-95\% significance, calculated from $t$ statistics. We find that these coefficients have about the same values for all instruments. The MIPAS, SCIAMACHY, and SMR $d_{1}$ coefficients agree remarkably well. The SMR coefficients take high values below $80 \mathrm{~km}$, but these values are not significant. The ACE-FTS coefficients, however, differ substantially at latitudes larger than $60^{\circ}$. The $d_{2}$ coefficients agree not as strongly, but they are also 1 order of magnitude smaller in general. The sine coefficients $e_{1}$ and $e_{2}$ are not shown, but they agree on a similar level with a slightly smaller magnitude than their cosine counterparts.

Figures 18 and 19 show the coefficients $b$ and $c$ of the Lyman- $\alpha$ UV index and the Kp geomagnetic index. The 

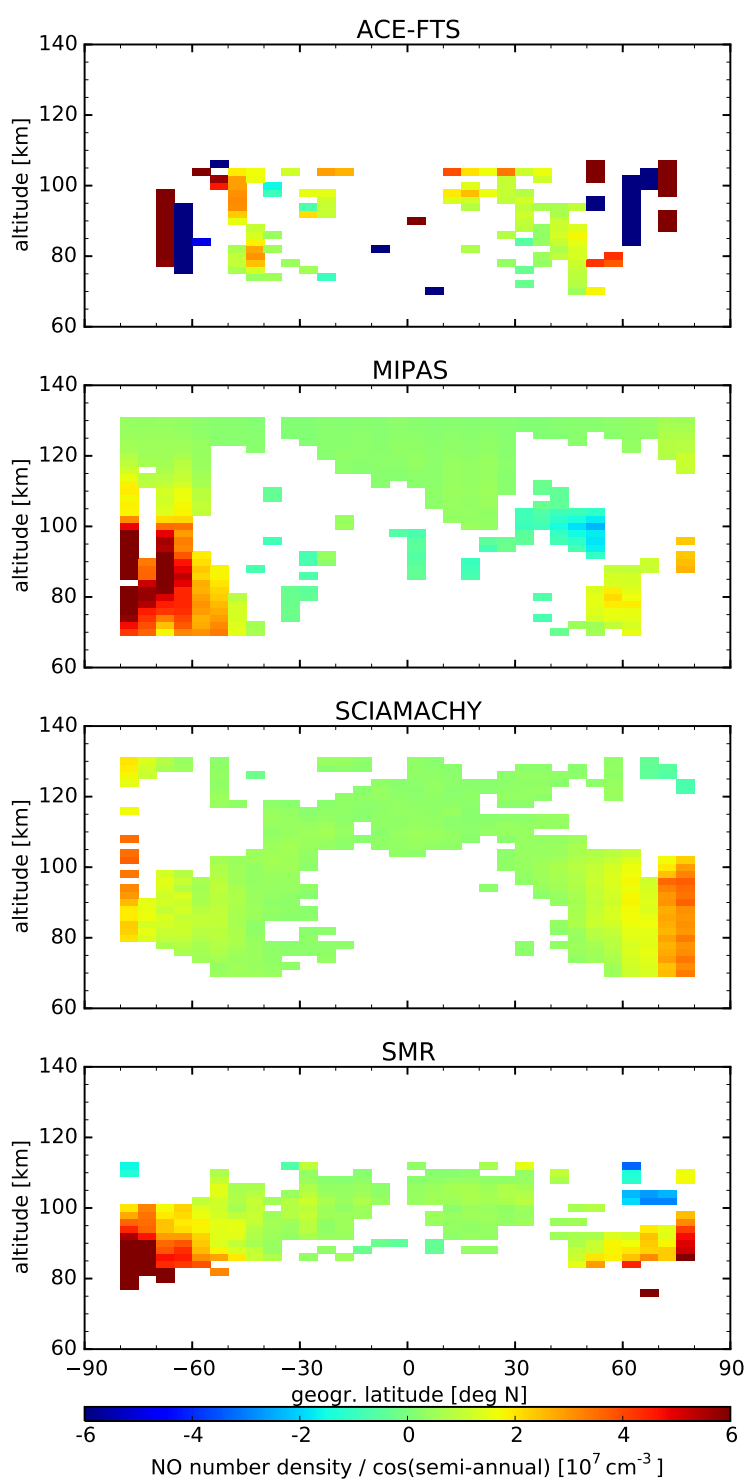

Figure 17. NO regression coefficient $d_{2}$ of the semi-annual cycle (cosine part) as in Fig 16.

latitude-altitude patterns of both coefficients are similar for all instruments. The SMR and SCIAMACHY Lyman- $\alpha$ coefficients $b$ are enhanced at all latitudes in a band from 95 to $110 \mathrm{~km}$. This band of larger values is less pronounced in the ACE-FTS and MIPAS data. The coefficients are also consistently enhanced at polar latitudes from 80 to $100 \mathrm{~km}$ in the ACE-FTS, MIPAS, and SMR data. The coefficients derived from SCIAMACHY data are increased only in the northern polar region.

We observe enhanced Kp coefficients $c$ in the main production regions north and south with all instruments. The magnitude of these coefficients is smallest in the SCIAMACHY data because polar night measurements were rare and only performed during a period of low solar activity.
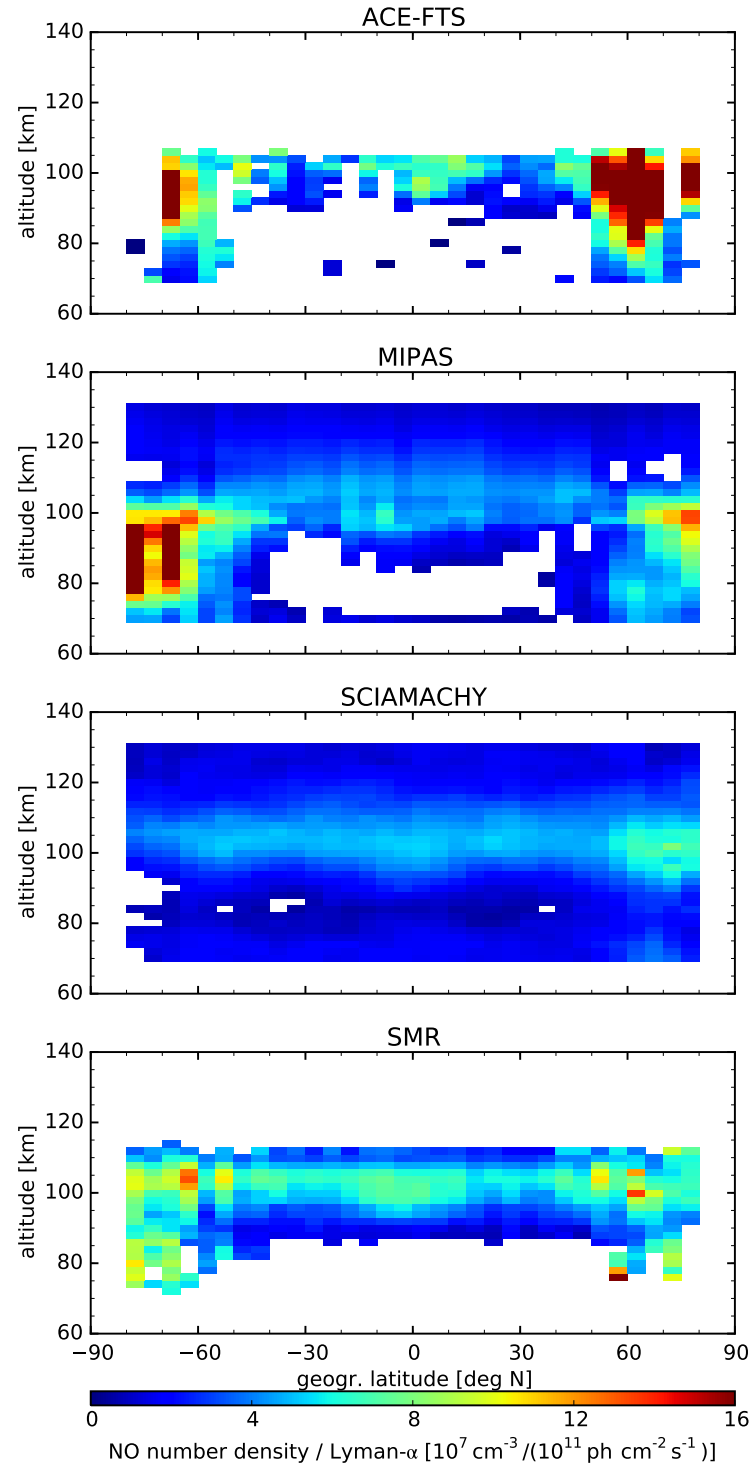

Figure 18. NO regression coefficient $b$ of the long-term solar UV variations from the Lyman- $\alpha$ index as in Fig. 16.

ACE-FTS also provides only few data points at the beginning and the end of the polar night; see Figs. 1 and 2. But in contrast to SCIAMACHY, ACE-FTS measured also during a period of higher solar activity, which explains the larger Kp coefficients. The patterns, however, are consistent with the data from the other instruments.

Figure 20 shows the direct comparison of three regression coefficients $-d_{1}, b$, and $c-$ at four selected altitudelatitude points. We selected one high latitude $\left(67.5^{\circ} \mathrm{N}\right)$ and one low latitude $\left(2.5^{\circ} \mathrm{N}\right)$, together with one altitude in the mesosphere $(85 \mathrm{~km})$ and one near the maximal NO density in the lower thermosphere $(105 \mathrm{~km})$. Due to the nature of the ACE-FTS measurements (solar occultation), its seasonal coefficient $d_{1}$ is unreliable at high latitudes (upper row). Note that the SMR measurements at $85 \mathrm{~km}$ at low latitudes are 

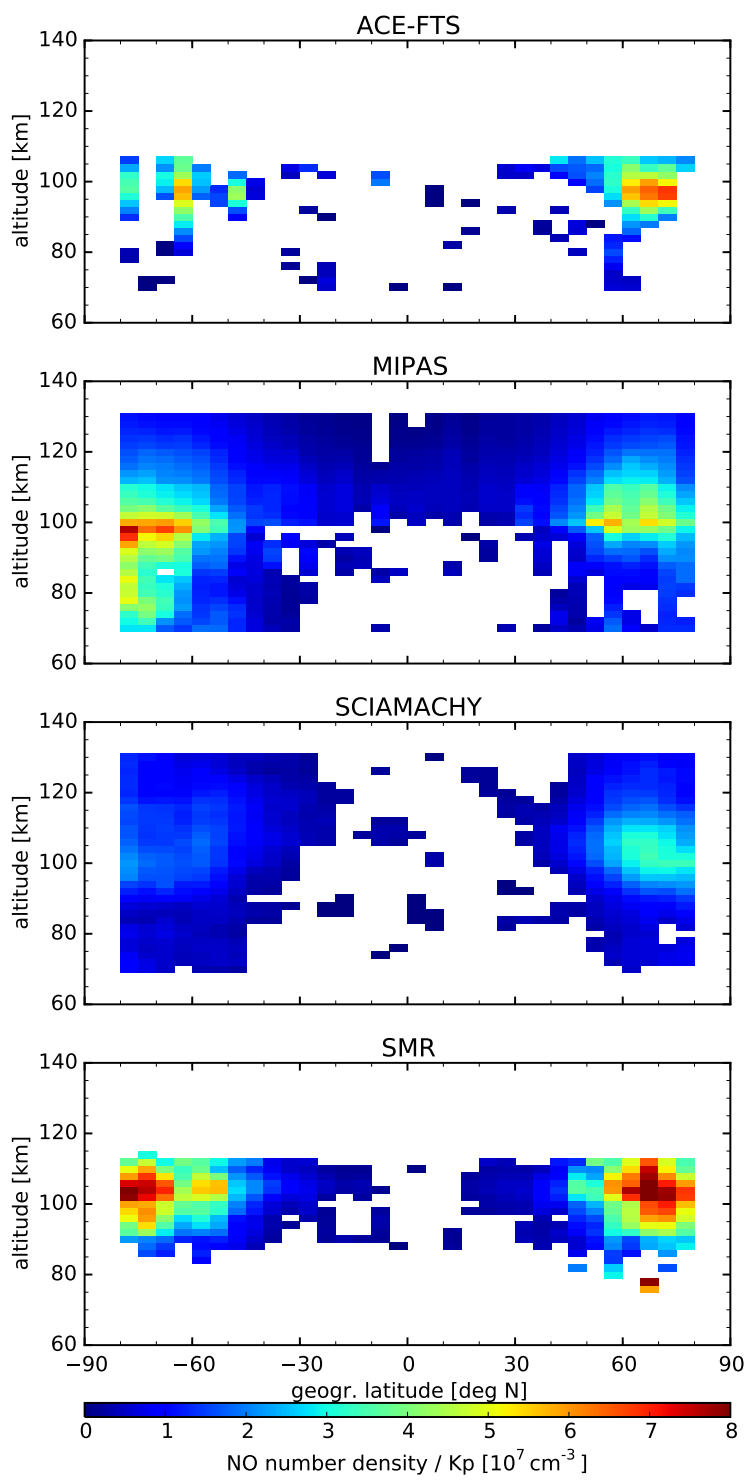

Figure 19. NO regression coefficient $c$ of the short-term geomagnetic variations from the Kp index as in Fig. 16.

too sparse (see Fig. 1) to derive significant regression coefficients. We find consistent coefficients at these four locations, with some exceptions at higher altitudes. The SMR seasonal $\left(d_{1}\right)$ and $\mathrm{Kp}(c)$ coefficients differ from the other four at $67.5^{\circ} \mathrm{N}$. At $2.5^{\circ} \mathrm{N}$, the notable exceptions are the SCIAMACHY seasonal coefficient and the SMR Lyman- $\alpha$ coefficient.

Taking into account the instrument sampling patterns, the cross correlations between these three estimators vary in general within \pm 0.3 . Larger (anti-)correlations were found in the Lyman $-\alpha / \mathrm{Kp}$ cross correlations considering the SCIAMACHY sampling at latitudes south of $60^{\circ} \mathrm{S}$ and the ACEFTS sampling between 50 and $65^{\circ} \mathrm{N}$.
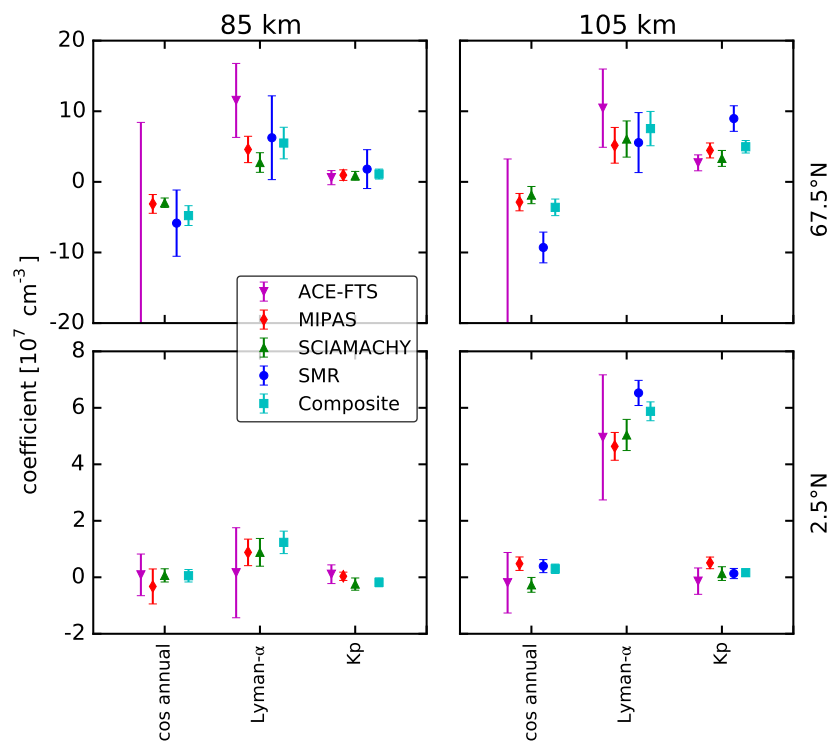

Figure 20. Direct comparison of the regression coefficients $d_{1}, b$, and $c$ at two altitudes ( $85 \mathrm{~km}$, left column; 105, right column) and two latitudes $\left(67.5^{\circ} \mathrm{N}\right.$, upper row; $2.5^{\circ} \mathrm{N}$, lower row). The error bars indicate the $95 \%$ confidence interval of the coefficient calculated using the $t$ test.

\subsection{Discussion}

We note that the transfer function 1 is by no means intended to capture all variations of NO in the MLT region. In particular, it does not account for diurnal or tidal variations. As discussed in Sect. 5.4, these variations add to the differences between ACE-FTS and SMR compared to MIPAS and SCIAMACHY.

The residuals shown in Figs. 11-14 and the relative mean residual distributions shown in Fig. 15 give a mixed impression. The ACE-FTS and SMR residuals are consistently larger than the transfer function only at high northern latitudes between 80 and $100 \mathrm{~km}$, while MIPAS and SCIAMACHY residuals are smaller in the same region. This hints at systematic differences from diurnal variability as discussed in Sect 5.4. However, we do not find similar systematic differences in other regions. The MIPAS and SCIAMACHY residuals as well as the ACE-FTS and SMR residuals are not always synchronously larger or smaller compared to the transfer function. This indicates that other effects beside diurnal variations are important.

The different vertical resolutions of MIPAS and SCIAMACHY, as discussed in Sect. 5.3, affect the residuals above $100 \mathrm{~km}$. In particular between 105 and $125 \mathrm{~km}$, this results in positive residuals of MIPAS densities and negative residuals of SCIAMACHY densities; see Fig. 15. 


\section{Conclusions}

In this study, we compared the measurements from four instruments, three limb sounders and one solar occultation instrument, using different spectral ranges: infrared, submillimetre waves, and ultraviolet. Despite these different methods and accompanying different retrieval strategies, the nitric oxide daily zonal mean densities of all four instruments are consistent during the comparison time period.

We find that the NO number density time series agree well; almost all data points lie within the statistical error bars (equal to the $95 \%$ confidence interval) of the daily zonal mean values. Additionally, considering the different vertical resolutions and sometimes large systematic uncertainties, we get a consistent data set. The remaining differences are most likely caused by the different MLT measurement schedules and latitude-time coverage of the instruments. For example, SCIAMACHY provides only daytime measurements and therefore less data at high latitudes at polar winter, where the other instruments observe enhanced NO values. This biases the SCIAMACHY daily zonal mean NO number densities to smaller values compared to the other instruments. We observe this effect clearly in the comparisons shown in Sect. 4.

The medians of vertical profile differences in three geographic regions $\left(90-50^{\circ} \mathrm{S}, 50^{\circ} \mathrm{S}-50^{\circ} \mathrm{N}\right.$, and $50-90^{\circ} \mathrm{N}$ ) show that the NO number densities agree in general within $\pm 50 \%$. However, we found larger differences up to $100 \%$ in regions where the coincident statistics are very low; see, for example, Fig. 8. We also observed that MIPAS measured substantially larger densities than all other instruments between 100 and $120 \mathrm{~km}$. This excess, in particular compared to SCIAMACHY, lessens significantly after applying the MIPAS averaging kernels to the SCIAMACHY densities. It is likely that the remaining MIPAS high bias around $110 \mathrm{~km}$ is introduced by an inappropriate temperature a priori (MSIS, known to be too low in this region) which maps onto the retrieval. But we identified no other systematic feature between the four instruments.
We set up a simple transfer function for the NO number density $n_{\mathrm{NO}}$ on non-coincident days in Sect. 6. This multilinear regression model 1 describes all time series well, accounting for annual and semi-annual variations and for longterm solar and short-term geomagnetic variations using the Lyman- $\alpha$ UV index and the Kp index. We should note that this method involves jointly fitting data sets with different local times, geolocations, and temporal frequencies. It may therefore introduce a bias in the final result of the fit. However, our aim is not to provide a model for NO in the MLT but to use this regression fit as a transfer function to check the consistency of temporally mismatched observations. Evaluating the residuals of the different data sets shows that the $\mathrm{NO}$ number densities are almost always consistent within $\pm 30 \%$. Single larger differences occur either at high southern latitudes (SCIAMACHY) or at altitudes close to the edge of the sensitivity range of the instrument (ACE-FTS); see Fig. 15. These differences lie well within the known systematic uncertainties and variations introduced by effects not considered here.

We also performed the regression analysis on an individual instrument basis and obtained consistent coefficients in the important altitude region. In particular, we found consistent responses to the estimators related to solar and geomagnetic variability. These estimators can be further used as an empirical model of NO in the middle atmosphere, which is particularly useful for climate models. 
Appendix A: Zonal mean data
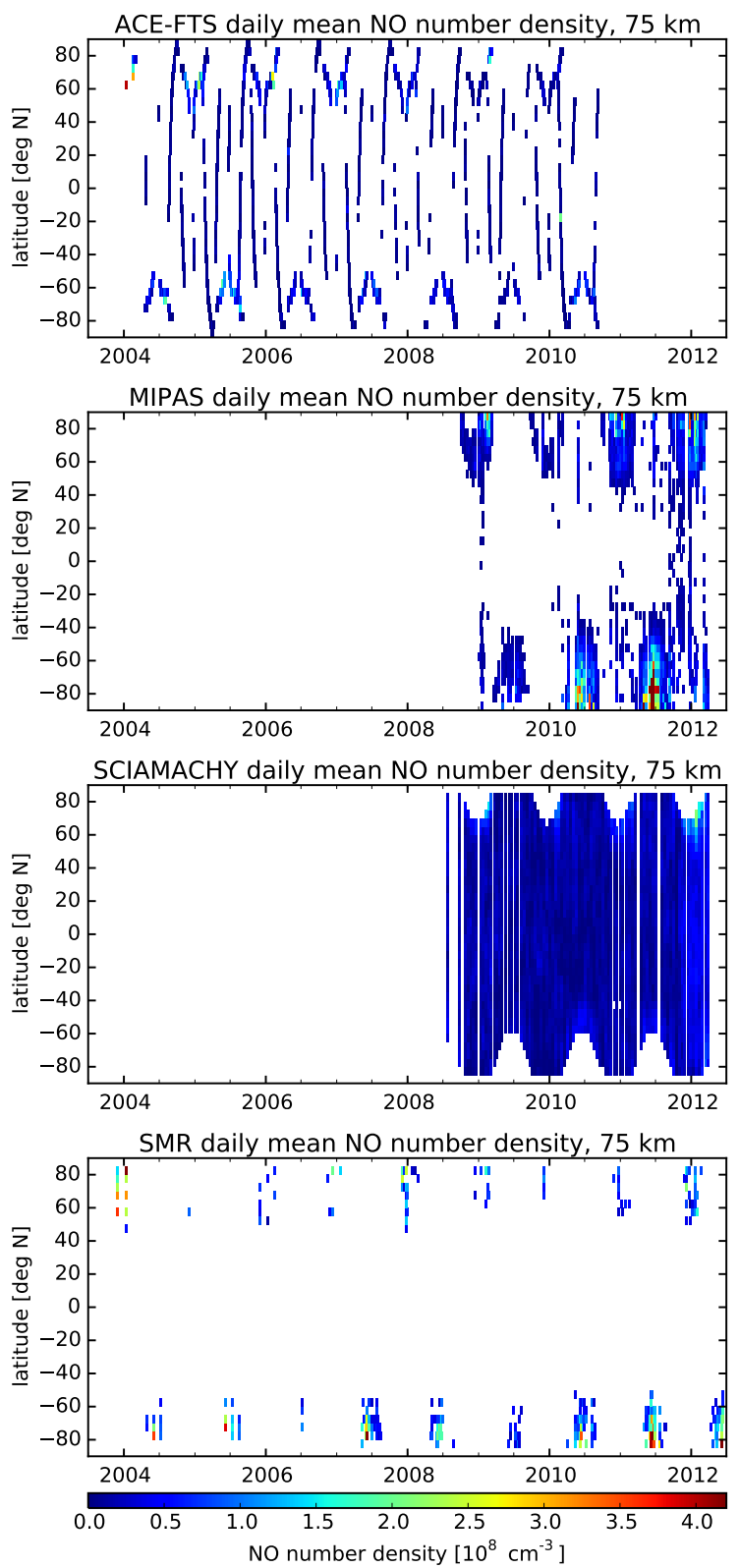

Figure A1. NO zonal mean time series at $75 \mathrm{~km}$ from ACE-FTS, MIPAS, SCIAMACHY, and SMR (from top to bottom).
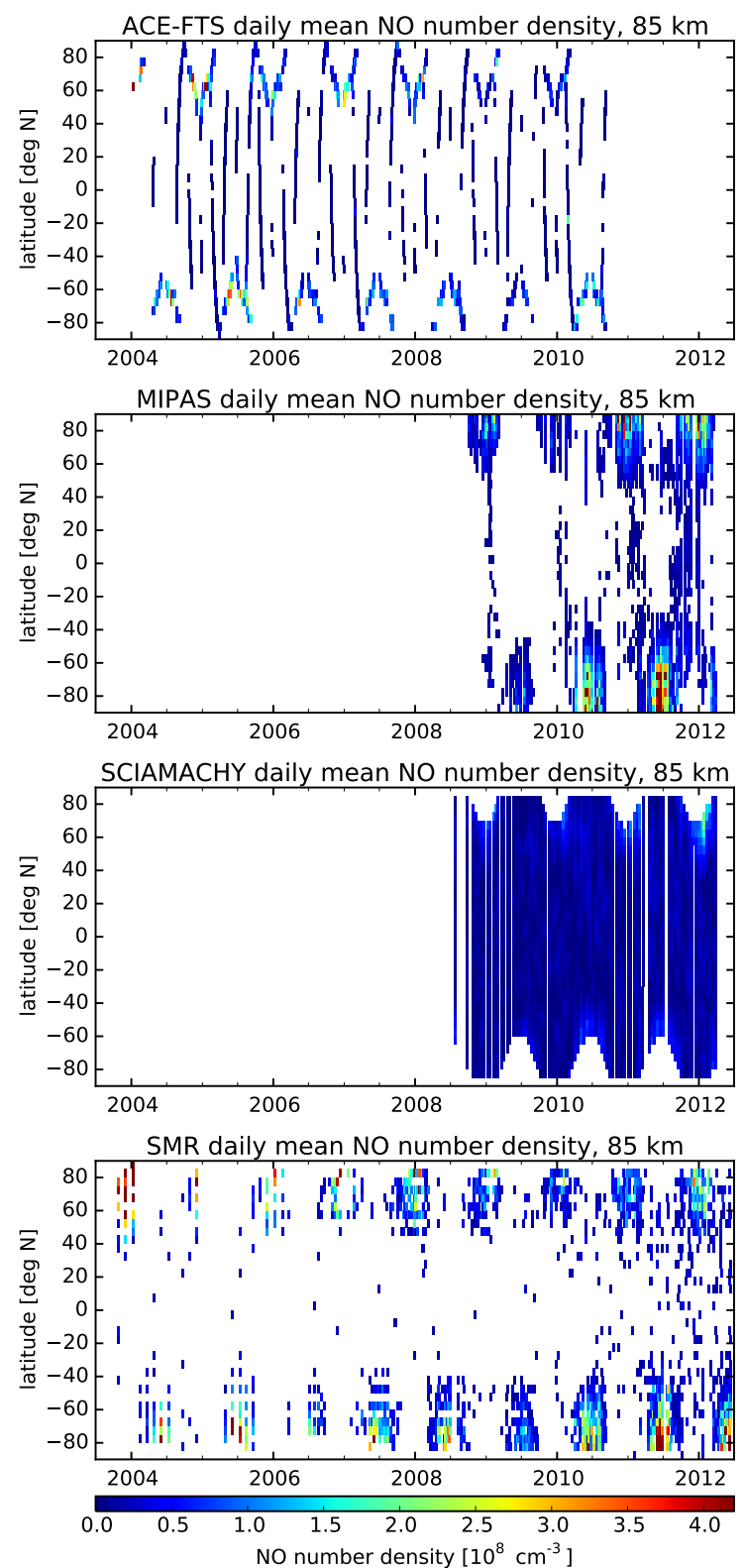

Figure A2. NO zonal mean time series at $85 \mathrm{~km}$ from ACE-FTS, MIPAS, SCIAMACHY, and SMR (from top to bottom). 

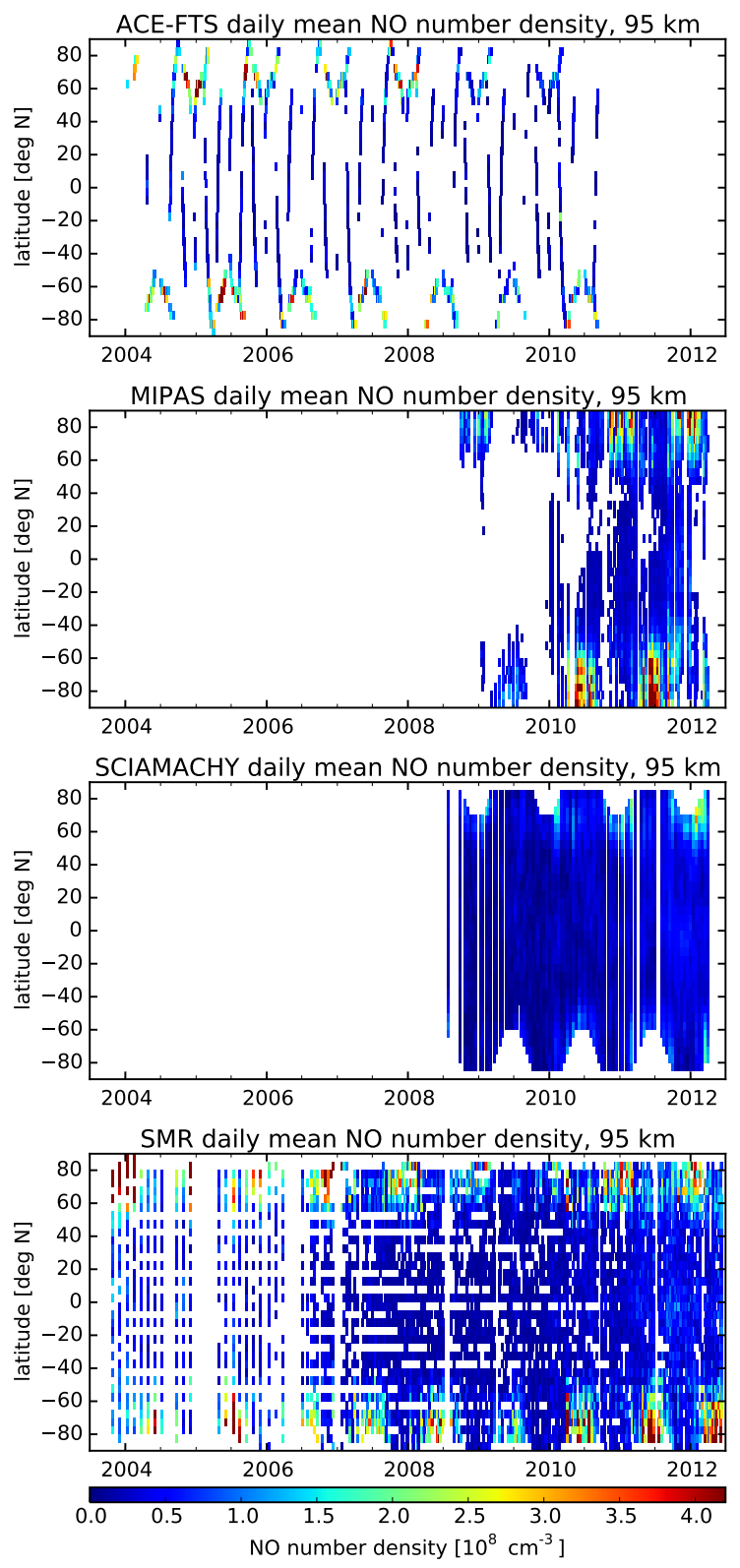

Figure A3. NO zonal mean time series at $95 \mathrm{~km}$ from ACE-FTS, MIPAS, SCIAMACHY, and SMR (from top to bottom).
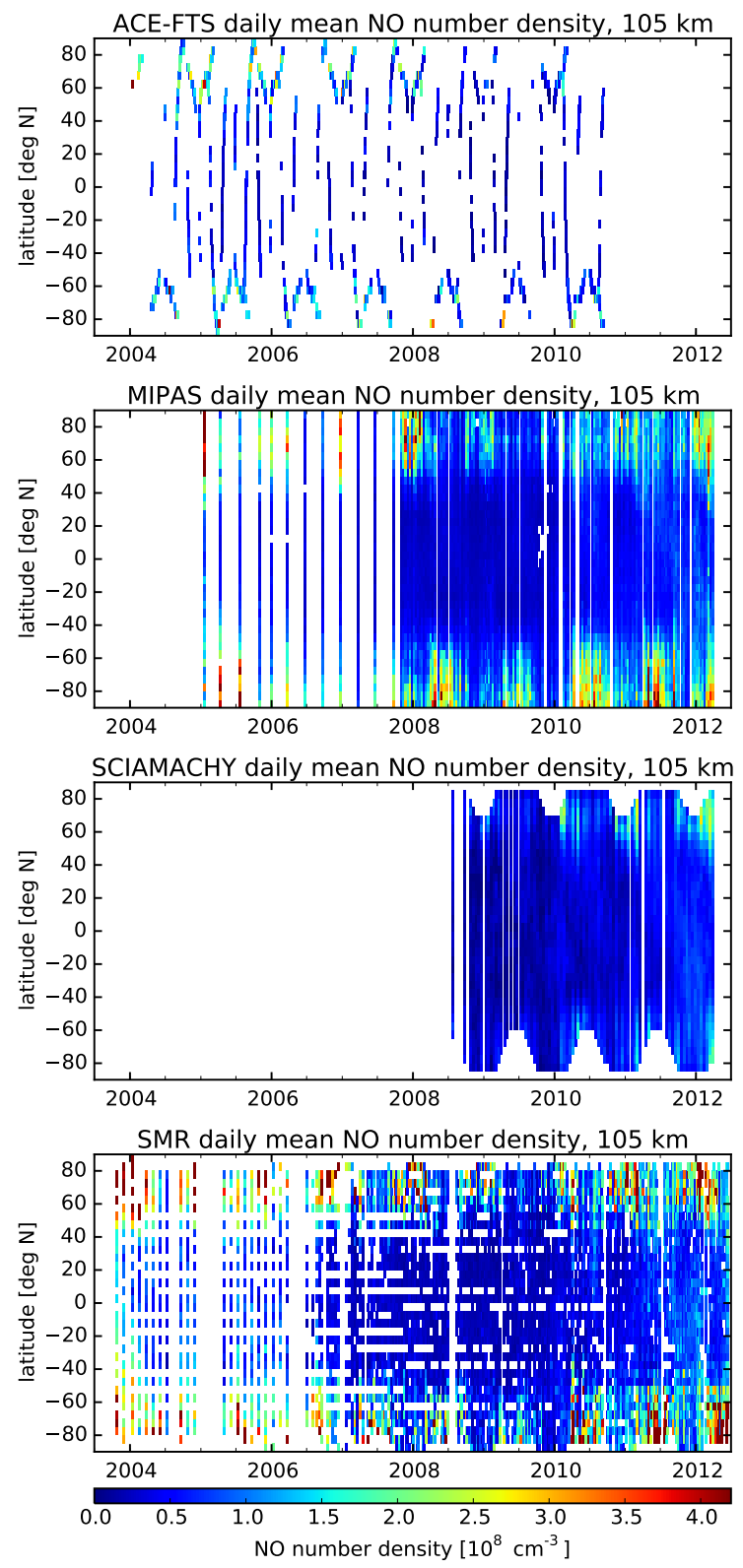

Figure A4. NO zonal mean time series at $105 \mathrm{~km}$ from ACE-FTS, MIPAS, SCIAMACHY, and SMR (from top to bottom). 

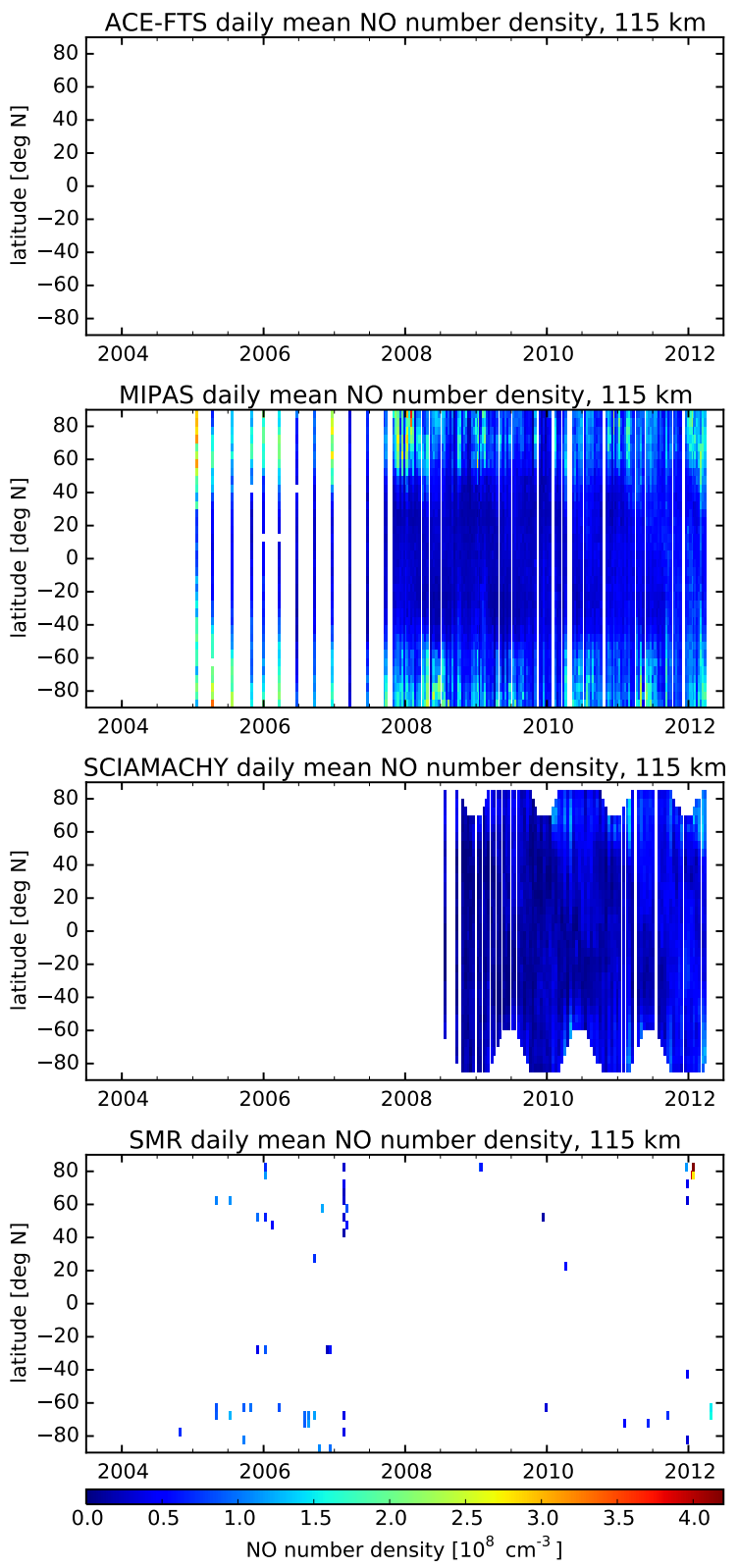

Figure A5. NO zonal mean time series at $115 \mathrm{~km}$ from ACE-FTS, MIPAS, SCIAMACHY, and SMR (from top to bottom). 
Appendix B: Time series

\section{B1 Northern Hemisphere}
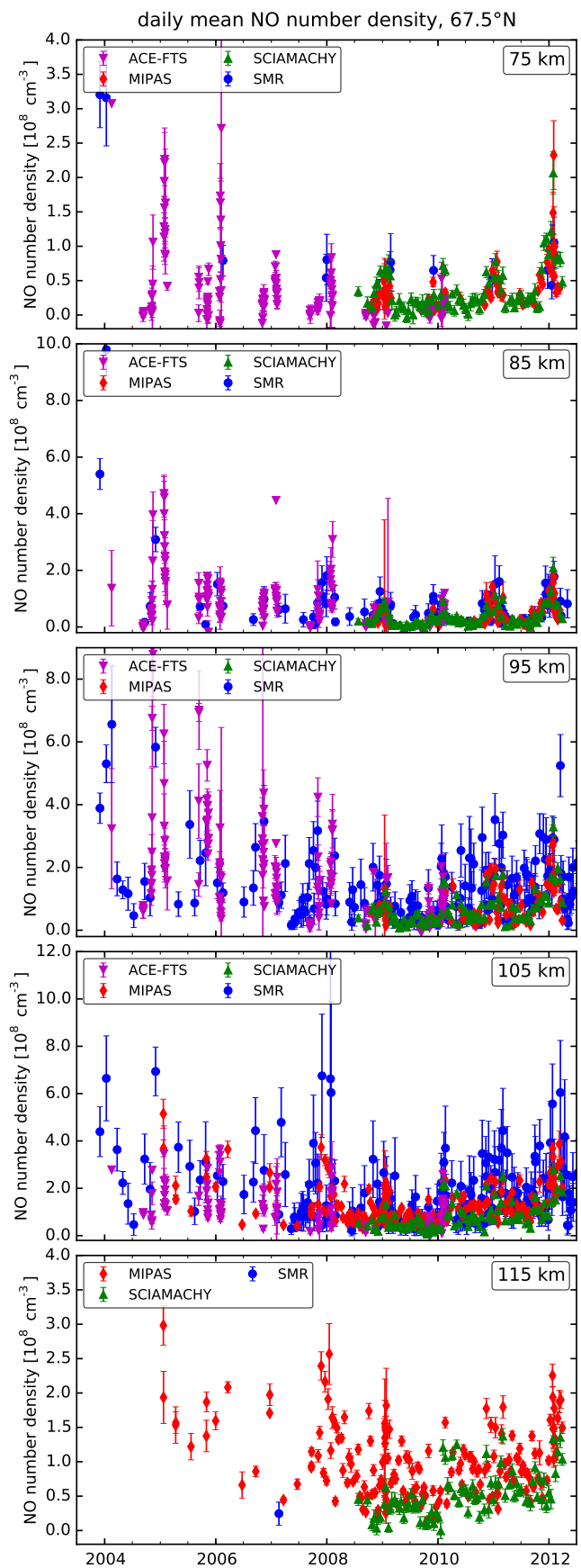

Figure B1. NO time series comparison of all four instruments at $67.5^{\circ} \mathrm{N}$, for $75 \mathrm{~km}, 85 \mathrm{~km}, 95 \mathrm{~km}, 105 \mathrm{~km}$, and $115 \mathrm{~km}$ (from top to bottom).

\section{B2 Southern Hemisphere}

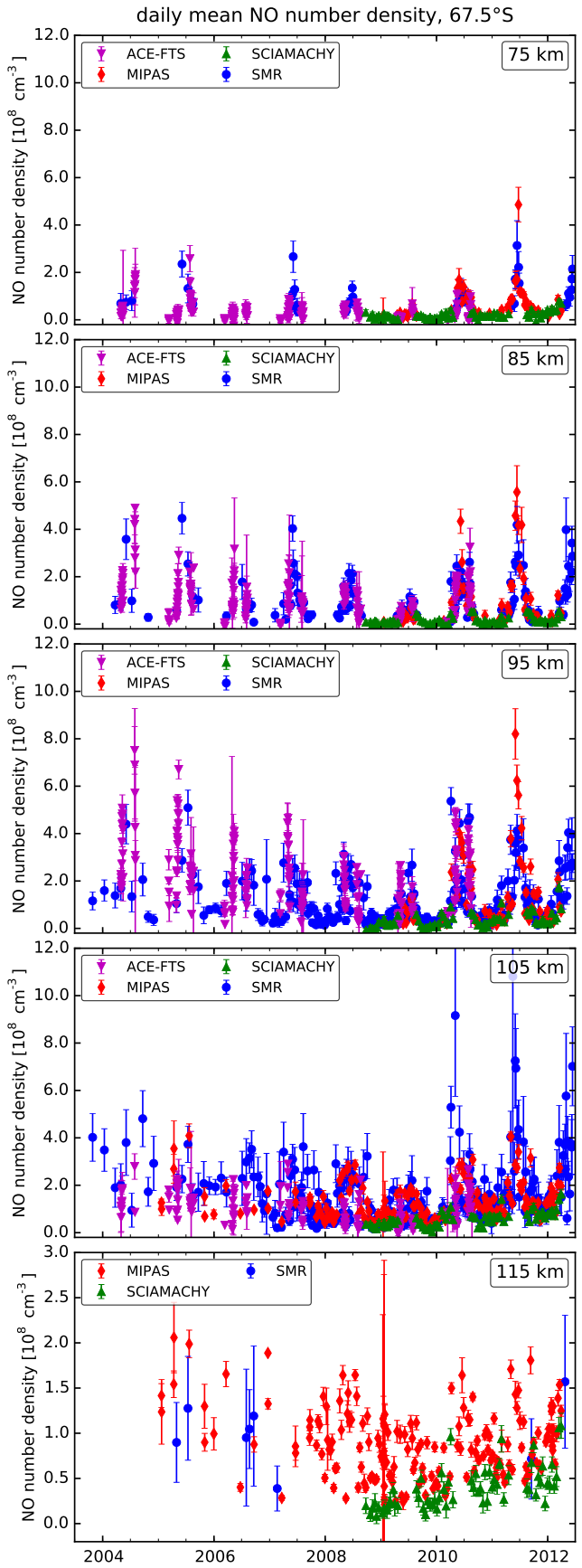

Figure B2. NO time series comparison of all four instruments at $67.5^{\circ} \mathrm{S}$, for $75 \mathrm{~km}, 85 \mathrm{~km}, 95 \mathrm{~km}, 105 \mathrm{~km}$, and $115 \mathrm{~km}$ (from top to bottom). 


\section{B3 Middle and low latitudes}
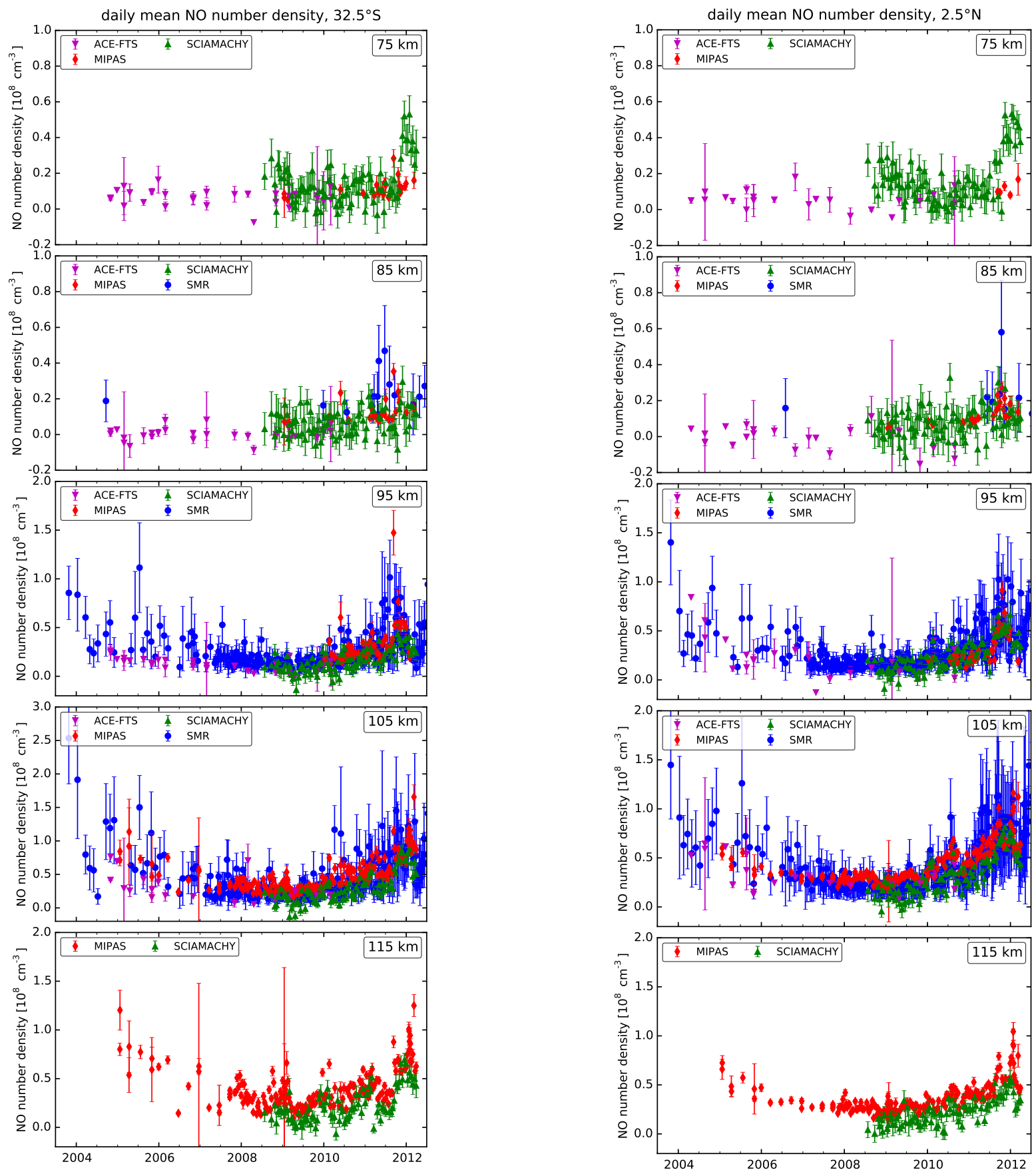

Figure B3. NO time series comparison of all four instruments at $32.5^{\circ} \mathrm{S}$, for $75 \mathrm{~km}, 85 \mathrm{~km}, 95 \mathrm{~km}, 105 \mathrm{~km}$, and $115 \mathrm{~km}$ (from top to bottom).

Figure B4. NO time series comparison of all four instruments at $2.5^{\circ} \mathrm{N}$, for $75 \mathrm{~km}, 85 \mathrm{~km}, 95 \mathrm{~km}, 105 \mathrm{~km}$, and $115 \mathrm{~km}$ (from top to bottom). 
Appendix C: Multi-linear regression analysis

C1 Northern Hemisphere

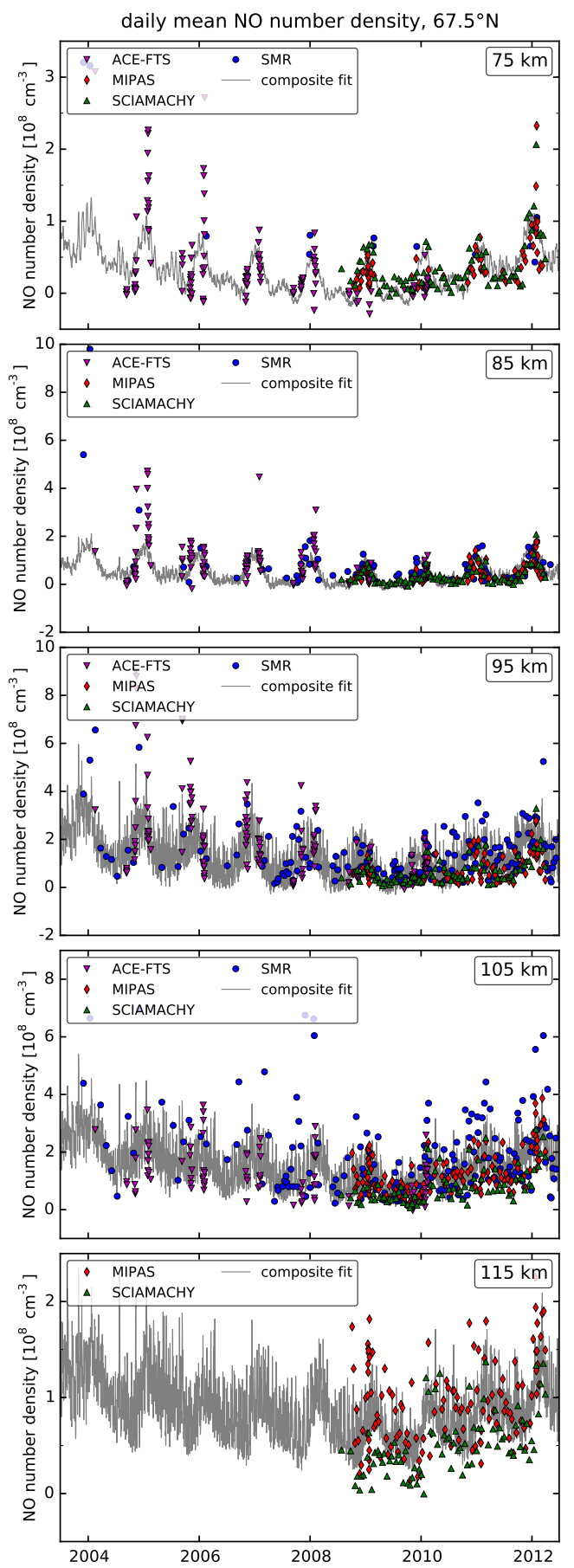

Figure C1. NO time series regression results at $67.5^{\circ} \mathrm{N}$, for $75 \mathrm{~km}$, $85 \mathrm{~km}, 95 \mathrm{~km}, 105 \mathrm{~km}$, and $115 \mathrm{~km}$ (from top to bottom).

\section{C2 Southern Hemisphere}
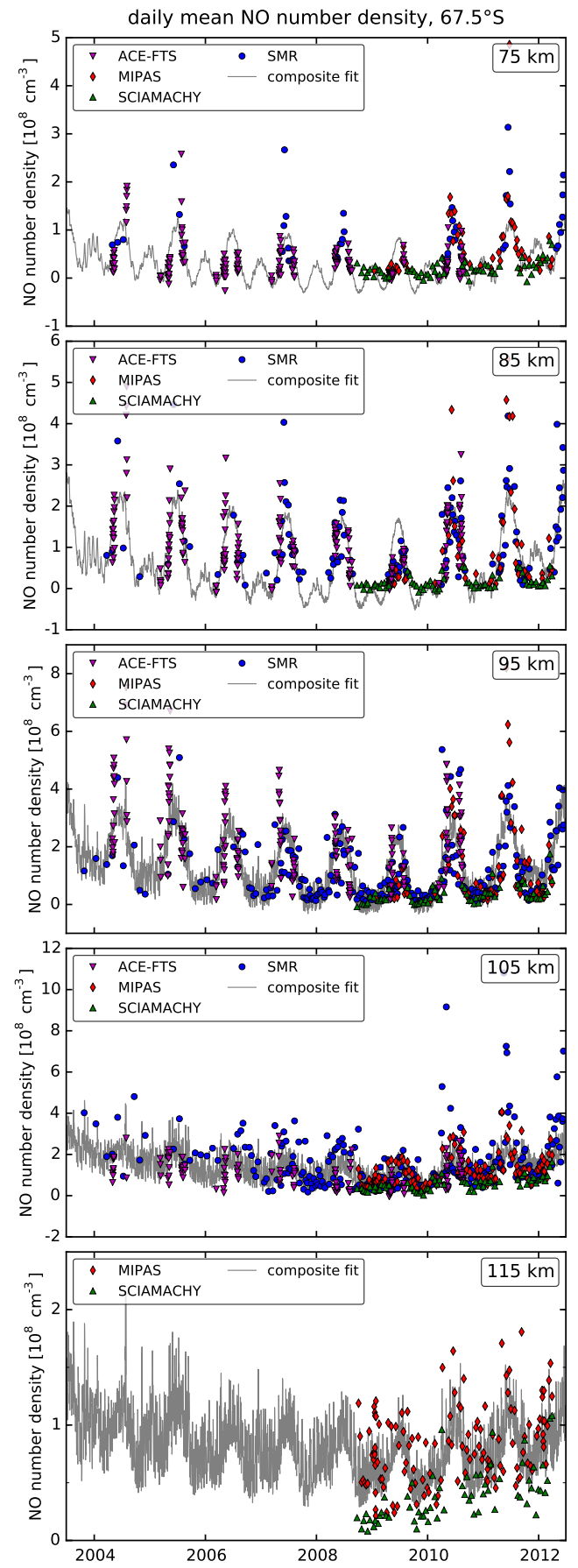

Figure C2. NO time series regression results at $67.5^{\circ} \mathrm{S}$, for $75 \mathrm{~km}$, $85 \mathrm{~km}, 95 \mathrm{~km}, 105 \mathrm{~km}$, and $115 \mathrm{~km}$ (from top to bottom). 


\section{C3 Middle and low latitudes}
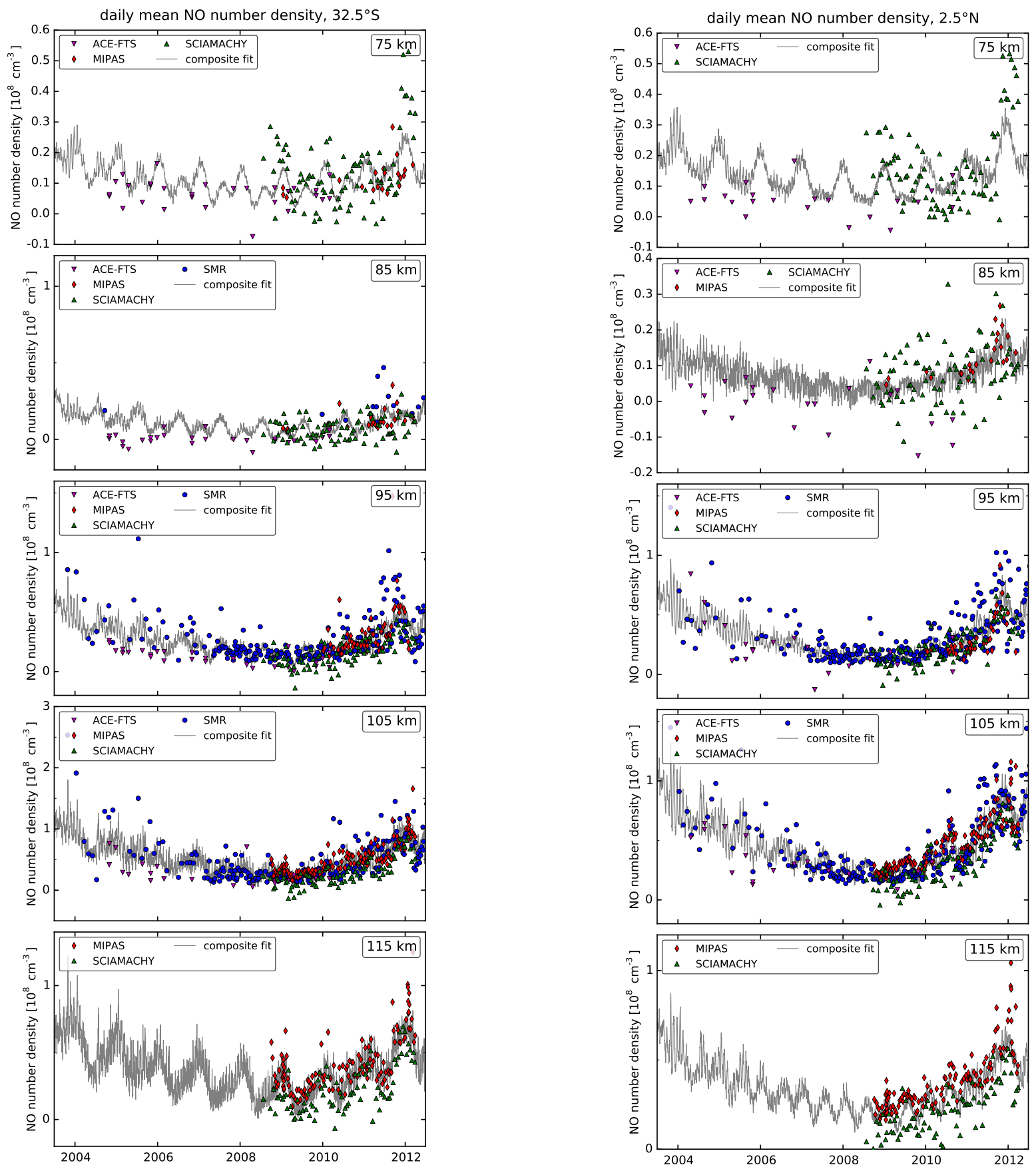

Figure C3. NO time series regression results at $32.5^{\circ} \mathrm{S}$, for $75 \mathrm{~km}$, $85 \mathrm{~km}, 95 \mathrm{~km}, 105 \mathrm{~km}$, and $115 \mathrm{~km}$ (from top to bottom).

Figure C4. NO time series regression results at $2.5^{\circ} \mathrm{N}$, for $75 \mathrm{~km}$, $85 \mathrm{~km}, 95 \mathrm{~km}, 105 \mathrm{~km}$, and $115 \mathrm{~km}$ (from top to bottom). 
Acknowledgements. S. Bender and M. Sinnhuber thank the Helmholtz Society for funding this project under the grant number VH-NG-624. The IAA team (M. López-Puertas and B. Funke) were supported by the Spanish MINECO under grant AYA2011-23552 and EC FEDER funds. The SCIAMACHY project was funded by the German Aerospace Center (DLR), the Dutch Space Agency, SNO, and the Belgian Science Policy Office (BELSPO). ESA funded the Envisat project. The University of Bremen as the principal investigator has led the scientific support and development of SCIAMACHY and the scientific exploitation of its data products. The Atmospheric Chemistry Experiment (ACE), also known as SCISAT, is a Canadian-led mission mainly supported by the Canadian Space Agency and the Natural Sciences and Engineering Research Council of Canada. Odin is a Swedish-led satellite project funded jointly by Sweden (SNSB), Canada (CSA), Finland (TEKES), France (CNES) and the Third-Party Missions programme of the European Space Agency (ESA). The provision of MIPAS level-1b data by ESA is gratefully acknowledged. We acknowledge support by the Deutsche Forschungsgemeinschaft and the Open Access Publishing Fund of the Karlsruhe Institute of Technology.

The article processing charges for this open-access publication were covered by a Research

Centre of the Helmholtz Association.

Edited by: M. Riese

\section{References}

Bailey, S. M., Barth, C. A., and Solomon, S. C.: A model of nitric oxide in the lower thermosphere, J. Geophys. Res., 107, 1205, doi:10.1029/2001JA000258, 2002.

Barnett, J. and Corney, M.: A middle atmosphere temperature reference model from satellite measurements, Adv. Space Res., 5, 125-134, doi:10.1016/0273-1177(85)90369-2, 1985.

Barth, C. A., Mankoff, K. D., Bailey, S. M., and Solomon, S. C.: Global observations of nitric oxide in the thermosphere, J. Geophys. Res., 108, 1027, doi:10.1029/2002JA009458, 2003.

Bender, S., Sinnhuber, M., Burrows, J. P., Langowski, M., Funke, B., and López-Puertas, M.: Retrieval of nitric oxide in the mesosphere and lower thermosphere from SCIAMACHY limb spectra, Atmos. Meas. Tech., 6, 2521-2531, doi:10.5194/amt-62521-2013, 2013.

Bermejo-Pantaleón, D., Funke, B., López-Puertas, M., GarcíaComas, M., Stiller, G. P., von Clarmann, T., Linden, A., Grabowski, U., Höpfner, M., Kiefer, M., Glatthor, N., Kellmann, S., and Lu, G.: Global observations of thermospheric temperature and nitric oxide from MIPAS spectra at $5.3 \mu \mathrm{m}$, J. Geophys. Res., 116, A10313, doi:10.1029/2011JA016752, 2011.

Bernath, P. F., McElroy, C. T., Abrams, M. C., Boone, C. D., Butler, M., Camy-Peyret, C., Carleer, M., Clerbaux, C., Coheur, P.-F., Colin, R., DeCola, P., DeMazière, M., Drummond, J. R., Dufour, D., Evans, W. F. J., Fast, H., Fussen, D., Gilbert, K., Jennings, D. E., Llewellyn, E. J., Lowe, R. P., Mahieu, E., McConnell, J. C., McHugh, M., McLeod, S. D., Michaud, R., Midwinter, C., Nassar, R., Nichitiu, F., Nowlan, C., Rinsland, C. P., Rochon, Y. J., Rowlands, N., Semeniuk, K., Simon, P., Skel- ton, R., Sloan, J. J., Soucy, M.-A., Strong, K., Tremblay, P., Turnbull, D., Walker, K. A., Walkty, I., Wardle, D. A., Wehrle, V., Zander, R., and Zou, J.: Atmospheric Chemistry Experiment (ACE): Mission overview, Geophys. Res. Lett., 32, L15S01, doi:10.1029/2005GL022386, 2005.

Boone, C. D., Nassar, R., Walker, K. A., Rochon, Y., McLeod, S. D., Rinsland, C. P., and Bernath, P. F.: Retrievals for the atmospheric chemistry experiment Fourier-transform spectrometer, Appl. Opt., 44, 7218-7231, doi:10.1364/AO.44.007218, 2005.

Boone, C. D., Walker, K. A., and Bernath, P. F.: The Atmospheric Chemistry Experiment ACE at 10: A Solar Occultation Anthology, chap. Version 3 Retrievals for the Atmospheric Chemistry Experiment Fourier Transform Spectrometer (ACE-FTS), 103127, A. Deepak Publishing, Hampton, Virginia, USA, 2013.

Bovensmann, H., Burrows, J. P., Buchwitz, M., Frerick, J., Noël, S., Rozanov, V. V., Chance, K. V., and Goede, A. P. H.: SCIAMACHY: Mission Objectives and Measurement Modes, J. Atmos. Sci., 56, 127-150, doi:10.1175/15200469(1999)056<0127:SMOAMM>2.0.CO;2, 1999.

Brook, R. J. and Arnold, G. C.: Applied Regression Analysis and Experimental Design, Statistics: A Series of Textbooks and Monographs (Vol. 62), CRC Press, 1st Edn., 256 pp., ISBN10:0824772520, 1985.

Burrows, J. P., Hölzle, E., Goede, A. P. H., Visser, H., and Fricke, W.: SCIAMACHY - scanning imaging absorption spectrometer for atmospheric chartography, Acta Astronaut., 35, 445-451, doi:10.1016/0094-5765(94)00278-T, 1995.

Chance, K. and Kurucz, R.: An improved high-resolution solar reference spectrum for earth's atmosphere measurements in the ultraviolet, visible, and near infrared, J. Quant. Spectrosc. Ra., 111, 1289-1295, doi:10.1016/j.jqsrt.2010.01.036, 2010.

DeLand, M. T. and Cebula, R. P.: Creation of a composite solar ultraviolet irradiance data set, J. Geophys. Res.-Space Phys., 113, A11103, doi:10.1029/2008JA013401, 2008.

DeWolfe, A. W., Wilson, A., Lindholm, D., Pankratz, C., Snow, M., and Woods, T.: Solar Irradiance Data Products at the LASP Interactive Solar IRradiance Data Center (LISIRD), in: AGU 2010 IN41B-1366, 2010.

Fischer, H., Birk, M., Blom, C., Carli, B., Carlotti, M., von Clarmann, T., Delbouille, L., Dudhia, A., Ehhalt, D., Endemann, M., Flaud, J. M., Gessner, R., Kleinert, A., Koopman, R., Langen, J., López-Puertas, M., Mosner, P., Nett, H., Oelhaf, H., Perron, G., Remedios, J., Ridolfi, M., Stiller, G., and Zander, R.: MIPAS: an instrument for atmospheric and climate research, Atmos. Chem. Phys., 8, 2151-2188, doi:10.5194/acp-8-2151-2008, 2008.

Funke, B., López-Puertas, M., Stiller, G., v. Clarmann, T., and Höpfner, M.: A new non-LTE retrieval method for atmospheric parameters from mipas-envisat emission spectra, Adv. Space Res., 27, 1099-1104, doi:10.1016/S0273-1177(01)001697, 2001.

Funke, B., López-Puertas, M., von Clarmann, T., Stiller, G. P., Fischer, H., Glatthor, N., Grabowski, U., Höpfner, M., Kellmann, S., Kiefer, M., Linden, A., Mengistu Tsidu, G., Milz, M., Steck, T., and Wang, D. Y.: Retrieval of stratospheric NOx from 5.3 and $6.2 \mu \mathrm{m}$ nonlocal thermodynamic equilibrium emissions measured by Michelson Interferometer for Passive Atmospheric Sounding (MIPAS) on Envisat, J. Geophys. Res., 110, D09302, doi:10.1029/2004JD005225, 2005. 
Funke, B., López-Puertas, M., García-Comas, M., Kaufmann, M., Höpfner, M., and Stiller, G.: GRANADA: A Generic RAdiative traNsfer AnD non-LTE population algorithm, J. Quant. Spectrosc. Radiat. Transfer, 113, 1771-1817, doi:10.1016/j.jqsrt.2012.05.001, 2012.

Funke, B., López-Puertas, M., Stiller, G. P., and von Clarmann, T.: Mesospheric and stratospheric NOy produced by energetic particle precipitation during 2002-2012, J. Geophys. Res., 119, 4429-4446, doi:10.1002/2013JD021404, 2014.

Kerzenmacher, T., Wolff, M. A., Strong, K., Dupuy, E., Walker, K. A., Amekudzi, L. K., Batchelor, R. L., Bernath, P. F., Berthet, G., Blumenstock, T., Boone, C. D., Bramstedt, K., Brogniez, C., Brohede, S., Burrows, J. P., Catoire, V., Dodion, J., Drummond, J. R., Dufour, D. G., Funke, B., Fussen, D., Goutail, F., Griffith, D. W. T., Haley, C. S., Hendrick, F., Höpfner, M., Huret, N., Jones, N., Kar, J., Kramer, I., Llewellyn, E. J., López-Puertas, M., Manney, G., McElroy, C. T., McLinden, C. A., Melo, S., Mikuteit, S., Murtagh, D., Nichitiu, F., Notholt, J., Nowlan, C., Piccolo, C., Pommereau, J.-P., Randall, C., Raspollini, P., Ridolfi, M., Richter, A., Schneider, M., Schrems, O., Silicani, M., Stiller, G. P., Taylor, J., Tétard, C., Toohey, M., Vanhellemont, F., Warneke, T., Zawodny, J. M., and Zou, J.: Validation of $\mathrm{NO}_{2}$ and NO from the Atmospheric Chemistry Experiment (ACE), Atmos. Chem. Phys., 8, 5801-5841, doi:10.5194/acp-8-5801-2008, 2008.

LISIRD Data Systems Group: LISIRD: LASP Interactive Solar Irradiance Data Center, http://lasp.colorado.edu/lisird/ (last access: 30 September 2013), 2010.

Marsh, D. R. and Russell, J. M.: A tidal explanation for the sunrise/sunset anomaly in HALOE low-latitude nitric oxide observations, Geophys. Res. Lett., 27, 3197-3200, doi:10.1029/2000GL000070, 2000.

Merino, F., Murtagh, D., Ridal, M., Eriksson, P., Baron, P., Ricaud, P., and de la Noe, J.: Studies for the Odin sub-millimetre radiomoter: III. Performance simulations, Can. J. Phys., 80, $357-$ 373, doi:10.1139/P01-154, 2002.

Murtagh, D., Frisk, U., Merino, F., Ridal, M., Jonsson, A., Stegman, J., Witt, G., Eriksson, P., Jimenez, C., Megie, G., de la Noe, J., Ricaud, P., Baron, P., Pardo, J., Hauchcorne, A., Llewellyn, E., Degenstein, D., Gattinger, R., Lloyd, N., Evans, W., McDade, I., Haley, C., Sioris, C., von Savigny, C., Solheim, B., McConnell, J., Strong, K., Richardson, E., Leppelmeier, G., Kyrola, E., Auvinen, H., and Oikarinen, L.: An overview of the Odin atmospheric mission, Can. J. Phys., 80, 309-319, doi:10.1139/P01-157, 2002.

Neter, J., Kutner, M., Wasserman, W., and Nachtsheim, C.: Applied Linear Statistical Models, Irwin Series in Statistics, McGrawHill/Irwin, 4th Edn., 1408 pp., ISBN-10:0256117365, 1996.
NGDC and NOAA: Space Physics Interactive Data Resource (SPIDR), http://spidr.ngdc.noaa.gov/spidr/ (last access: 11 December 2013), 2011.

Nordh, H. L., von Schéele, F., Frisk, U., Ahola, K., Booth, R. S., Encrenaz, P. J., Hjalmarson, A., Kendall, D., Kyrölä, E., Kwok, S., Lecacheux, A., Leppelmeier, G., Llewellyn, E. J., Mattila, K., Mégie, G., Murtagh, D., Rougeron, M., and Witt, G.: The Odin orbital observatory, Astron. Astrophys., 402, L21-L25, doi:10.1051/0004-6361:20030334, 2003.

Oberheide, J. and Forbes, J. M.: Thermospheric nitric oxide variability induced by nonmigrating tides, Geophys. Res. Lett., 35 , 116814, doi:10.1029/2008GL034825, 2008.

Pérot, K., Urban, J., and Murtagh, D. P.: Unusually strong nitric oxide descent in the Arctic middle atmosphere in early 2013 as observed by Odin/SMR, Atmos. Chem. Phys., 14, 8009-8015, doi:10.5194/acp-14-8009-2014, 2014.

Raspollini, P., Carli, B., Carlotti, M., Ceccherini, S., Dehn, A., Dinelli, B. M., Dudhia, A., Flaud, J.-M., López-Puertas, M., Niro, F., Remedios, J. J., Ridolfi, M., Sembhi, H., Sgheri, L., and von Clarmann, T.: Ten years of MIPAS measurements with ESA Level 2 processor V6 - Part 1: Retrieval algorithm and diagnostics of the products, Atmos. Meas. Tech., 6, 2419-2439, doi:10.5194/amt-6-2419-2013, 2013.

Sheese, P. E., Strong, K., Gattinger, R. L., Llewellyn, E. J., Urban, J., Boone, C. D., and Smith, A. K.: Odin observations of Antarctic nighttime NO densities in the mesosphere-lower thermosphere and observations of a lower NO layer, J. Geophys. Res., 118, 7414-7425, doi:10.1002/jgrd.50563, 2013.

Urban, J., Lautie, N., Murtagh, D., Eriksson, P., Kasai, Y., Lossow, S., Dupuy, E., de la Noe, J., Frisk, U., Olberg, M., Le Flochmoen, E., and Ricaud, P.: Global observations of middle atmospheric water vapour by the Odin satellite: An overview, Planet. Space Sci., 55, 1093-1102, doi:10.1016/j.pss.2006.11.021, 2nd Annual Meeting of the Asia-Oceania-Geosciences-Society, Singapore, SINGAPORE, 20-24 June 2005, 2007.

von Clarmann, T., Glatthor, N., Grabowski, U., Höpfner, M., Kellmann, S., Kiefer, M., Linden, A., Tsidu, G. M., Milz, M., Steck, T., Stiller, G. P., Wang, D. Y., Fischer, H., Funke, B., GilLópez, S., and López-Puertas, M.: Retrieval of temperature and tangent altitude pointing from limb emission spectra recorded from space by the Michelson Interferometer for Passive Atmospheric Sounding (MIPAS), J. Geophys. Res., 108, 4736, doi:10.1029/2003JD003602, 2003.

Waymark, C., Walker, K. A., Boone, C. D., and Bernath, P. F.: ACEFTS version 3.0 data set: validation and data processing update, Ann. Geophys., 56, Fast Track 1, doi:10.4401/ag-6339, 2013. 